\title{
Gender differences among active reviewers: an investigation based on
}

\author{
Publons \\ Lin Zhang 1,2,3, *, Yuanyuan Shang ${ }^{1,2}$, Ying Huang ${ }^{1,2,3}$, Gunnar Sivertsen ${ }^{4}$ \\ ${ }^{1}$ Center for Studies of Information Resources, School of Information Management, Wuhan University, \\ China \\ ${ }^{2}$ Center for Science, Technology \& Education Assessment (CSTEA), Wuhan University, China \\ ${ }^{3}$ Centre for R\&D Monitoring (ECOOM) and Dept. MSI, KU Leuven, Belgium \\ ${ }^{4}$ Nordic Institute for Studies in Innovation, Research and Education, Toyen, Oslo, Norway
}

Corresponding email: linzhang1117@,whu.edu.cn

\begin{abstract}
Peer review of scientific manuscripts before publication is essential in scholarly publishing, and most active researchers hold relationships with a number of journals as both an author and a reviewer. There have been several studies focusing on gender balance in academic research and authorship, but fewer studies on our role as reviewers. Publons is a commercial website run by Clarivate Analytics that allows researchers to track and verify their peer review activities and be recognized for it. The platform features over 2 million researchers and 6.9 million reviews for more than 5,000 partnered journals, listing the most active reviewers as "top reviewers". Our study focuses on gender representation in this 'top reviewer' group while also looking at the countries, regions and research fields they represent, as well as the relationship between their roles as authors and reviewers. The results show that male reviewers dominate in almost all countries, regions, and research fields. Male reviewers generally contribute to review work more frequently than females; however, female reviewers write longer reviews. The correlations between reviewing activity and research activity are generally weak overall and within specific research fields. This may reflect that active reviewers are not necessarily the most productive researchers in their fields. What clearly emerges from our results is the need for more concern over gender representation in the quality assurance and gatekeeping functions of scholarly publishing.
\end{abstract}

Keywords: active reviewer; research activity; reviewing activity; gender differences; Publons 


\section{Introduction}

Peer review is the activity when reviewers assess other researchers' manuscripts before publishing, which is essential to the development of research and to the dissemination of scholarly publications. However, peer review activities are often overlooked. The time and efforts that each reviewer spends on reviewing activity have not been recognized by the academic evaluation system. As a result, many scholars tend to devote more time and energy to their research than to reviewing activity (Publons, 2018; Tite \& Schroter, 2007). At the same time, substantial growth in the number of manuscripts submitted to scholarly journals has increased the review "burden" on academics (Jubb, 2016; Kovanis et al., 2016). Clarivate Analytics (2018, p. 45) goes so far as to report signs of "reviewer fatigue" within academia. Hence, learning more about the people who provide reviews seems a reasonable starting point for any effort towards ensuring their well-being and supporting the quality assurance of this important gate-keeping function.

The fundamental principle of peer review is based on universalism. It claims that knowledge should be evaluated according to "preestablished impersonal criteria" rather than on particular facts about a person's social identity and status (Merton, 1973). However, a great number of previous studies stated that the acceptance of manuscripts is affected by reviewers' judgments influenced by external factors such as the author's gender, nationality, prestige, and affiliation (Bradshaw \& Courchamp, 2018; Fox et al., 2017; Fox \& Paine, 2019; Murray et al., 2019; Reingewertz \& Lutmar, 2018). Bias in peer review may exacerbate existing inequalities in science, whereby scholars accrue accumulative advantages via a priori status privileges. In the research on different biases in peer review, gender bias remains a specific concern (Demarest et al., 2014; Lerback \& Hanson, 2017; Murray et al., 2019). Many studies have found that the population of reviewers and editors are heavily dominated by males (Fox et al., 2017; Fox \& Paine, 2019), which may potentially limit gender diversity in academia and further hinder scientific production. Therefore, special attention is required to the gender differences among the reviewers and to understand their behavioral characteristics.

Research activity and reviewing activity are both important components of scholars' scientific careers. On the one hand, participation in peer review can foster expertise and may benefit academic productivity. On the other hand, engaging in reviewing activity requires plenty of time, which may negatively affect the time spent on research activity (Lerback \& Hanson, 2017; Willis, 2016). Furthermore, while reviewing activity has not been widely recognized for promotions, positions and funding, publishing research results plays a critical role in scientists' career development (Käfer et al., 2018; Mendoza-Denton, 2017). Other duties also tend to increase with a scholar's seniority, leaving less time available for reviewing activity. Although previous studies have documented an interrelationship between reviewing and research activities, the relationship between the reviewing characteristics of reviewers and their academic performance as measured with bibliometrics has remained to be further explored. 
This study includes a correlation analysis of the two activities and possible gender differences in the relationship between research and reviewing activity are explored.

We will examine active reviewers across a broad spectrum of academic fields by selecting those recognized as "Top Reviewers" by Publons. Publons is a platform showcasing the peer review and journal editing history of over 2 million reviewers globally. According to the mission statement made by its owner -Clarivate Analytics, the platform is "to help researchers get recognition for their hidden peer review contributions". "We focus on the most active reviewers because, among 2 million reviewers, not all reviewers complete their profiles and update their Publons's accounts. Therefore, we chose reviewers awarded as 'Top 1\% in Field' in each of the 22 Essential Science Indicators (ESI) research areas. The information about these reviewers is more comprehensive and reliable for analysis. Focusing on these active reviewers, this study addresses the following three questions:

1) What are the gender statistics of reviewers by country, research field, and academic experience?

2) Are there any differences in the reviewing and research activities of reviewers by gender?

3) What are the relationships between the reviewing and research activities of reviewers? And are there any differences between the genders?

The next section of the paper covers the research background and outlines the data and methodology used to answer the research questions. The results of our analysis follow, and the paper concludes with a discussion of our findings, the limitations of this research, and directions for future inquiry.

\section{Research background}

\section{Gender differences in reviewing activity}

Gender differences in peer review have received extensive attention, with four main categories of studies. One category focuses on the differences in the representation of reviewers and editors. As the decision-making bodies of scientific journals, editorial boards tend to be composed of proportionately more males than females (Amrein et al., 2011; Cho et al., 2014; Mauleón et al., 2013; Morton \& Sonnad, 2007). This disparity is often more significant at more senior editorial levels (Addis \& Villa, 2003). In terms of the reviewers, a series of studies have shown that females remain underrepresented among reviewers of journal publications (Fox et al., 2016; Helmer et al., 2017; Lerback \& Hanson, 2017). Females are less likely to be invited as reviewers (Baucom et al., 2019). Moreover, although the proportion of female reviewers has increased over time, it changes slowly (Fox et al., 2019; Helmer et al., 2017).

The second category of studies focuses on the relationship between reviewers and editors. Some studies show that editors are more likely to select reviewers of the same gender (Helmer et al.,

\footnotetext{
1 https://publons.com/about/mission
} 
2017; Ross, 2017) and identify reciprocity preferences of editors in selecting reviewers (Bradshaw \& Courchamp, 2018). If the reviewers selected by editors are unevenly distributed across demographics, this could foster Matthew Effects (Merton, 1968). The work by Helmer et al. (2017) shows that editors select males more often than females as reviewers, which may lead to the overall lack of female reviewers (Buckley et al., 2014; Fox et al., 2016; Lerback \& Hanson, 2017).

The third category of studies is about the behavioral characteristics of the reviewers in their reviewing activity. In terms of the number of reviews, a self-report survey of reviewers found that males reviewed more manuscripts than females in the fields of ecology and evolution (Grod et al., 2008). Other studies have focused on the acceptance rate of reviewers. Results show that females are more likely to agree to review (Borja, 2015; Fox et al., 2016). As for the time spent on reviewing manuscripts, although females tend to take slightly longer to submit their reviews (Grod et al., 2008; Schmaling \& Blume, 2017; Wing et al.,2010), several studies have indicated that female reviewers possibly write more thoughtful reviews (Fox et al., 2016; Ortega, 2017; Wing et al., 2010).

The last category of studies looks at the gender differences in the review results and potential gender bias in the process of peer review. Some studies have shown that the acceptance rates for manuscripts are usually higher for males compared to females (Fox \& Paine, 2019; Murray et al., 2019). Some studies have also found that publications with male-sounding author names are rated higher during the peer-review process than those with female-sounding names (Knobloch-Westerwick et al., 2013; Krawczyk \& Smyk, 2016). One possible explanation is that reviewers or editors discriminate against papers by female authors during their assessments of manuscript quality, novelty, or significance (Fox \& Paine, 2019).

These studies have already provided a relatively comprehensive picture of gender differences in peer review. However, most of them have been conducted with data from specific or individual journals, such as Cell (Narasimhan, 2019), Frontiers journals (Helmer et al., 2017), The Lancet (Clark \& Horton, 2019), eLife (Murray et al., 2019). To provide insight of gender differences at a more granular level, a study with a broader range of reviewers' data and more diverse analytical dimensions is required. Hence, this study aims to analyze differences across all fields within the specific group of active reviewers and to observe possible gender differences in reviewing behaviors with more specific indicators, such as the number of reviews, the number journals reviewed for, and the average length of reviews. Furthermore, this study explores gender differences in different dimensions, such as region, discipline, and academic experience.

\section{Gender differences in research activity}

Gender differences in academia have been widely studied. Globally, females account for only $28.4 \%$ of all researchers, with a prolonged trend towards balance (UNESCO, 2015). The underrepresentation of females in the scientific workforce is conspicuous. Publishing research 
results is a critical factor in a scientist's career development. However, gender differences in academic productivity have proved a persistent problem. Many studies have shown that females publish significantly fewer articles than males (Bendels et al., 2018; Holman et al., 2018; Larivière et al., 2013). On the basis of existing research, this study further explores the gender differences in the research activities of active reviewers.

\section{Vicious circle for females in academia}

Gender inequality in scientific research has been extensively studied in terms of representation, productivity, influence, funding applications, and hiring (Abramo et al., 2009; Rørstad \& Aksnes, 2015; Sotudeh et al., 2018; van Arensbergen et al., 2012; van Den Besselaar \& Sandström, 2016, 2017). Gender inequality might lead to the lower representativeness of females in academia and may also have a negative effect on the publication activity. Scholarly publications are a common proxy of an individual's research contributions, which is a major factor in determining success when researchers compete for research grants (Doyle et al., 2015; Kaltman et al. 2014) or apply for promotion or tenure (Weisshaar, 2017). All these aspects are interconnected and may shape a vicious circle for females (Clark \& Horton, 2019; van den Besselaar \& Sandström, 2017; Walker, 2020), reinforcing gender inequality (Fig 1 (a)).

This vicious circle also exists in the scholarly publishing system, as shown in Fig 1(b). The research publication is the outcome of the collective efforts of authors, editors, and reviewers. For editors, to ensure high-quality peer reviews, it is vital to assign manuscripts to the appropriate reviewers (Black et al., 1998; Thurner \& Hanel, 2011). The selection of reviewers should meet specific criteria, including credibility (whether the reviewer has good recognition in the scientific community) and expertise (whether the reviewer is a specialist in the specific domain related to the manuscript) (Liu et al., 2014). Reviewers can be identified either through editors' professional networks or by searches of published literatures. To assist the procedures, there are some paper-reviewer assignment models that have been developed on the basis of the publications of scholars (Bianchi \& Squazzoni, 2015; Charlin \& Zemel, 2013; Liu et al., 2014). For reviewers, in ideal conditions, the manuscript should be judged by originality/novelty, plausibility/reliability, and value or usefulness (Langfeldt et al., 2020). However, the scholarly publishing system is influenced by gender bias, as mentioned above. Academia is currently male-dominated in many aspects, with females underrepresented and lagging behind significantly in academic productivity. Accordingly, females are much less likely to become editors and to be invited as reviewers. Due to reciprocity preferences in peer review, gender imbalances among editors and reviewers can in turn affect gender representation in the group of authors, which may further reinforce the vicious circle for females in the scholarly publishing system.

In the context of this vicious circle, the exploration of the relationship between reviewers' research and reviewing activities is necessary. It can provide more insight into how and to what extent this vicious circle exists in the academic publishing system. 
(a)

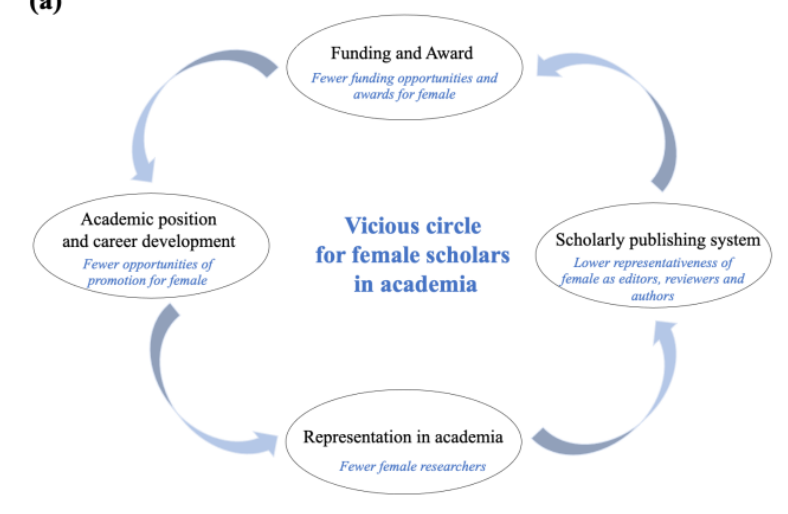

(b)

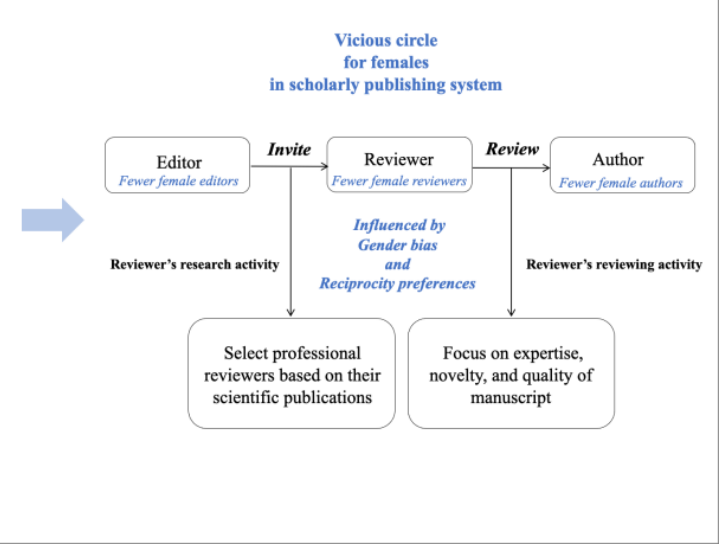

Figure 1. The vicious circle for female scholars in academia

\section{Data and methodology}

\section{Data collection and main indicators}

The data sample of active reviewers was gathered from Publons. In 2016, Publons launched the Global Peer Review Awards to provide recognition for reviewers. One of the award categories acknowledges the Top 1\% most active reviewers in a field, as determined by the number of verified pre-publication reviews conducted that year. ${ }^{2}$ Since 2018 , awards have been issued for each of the 22 fields of the Essential Science Indicators (ESI). There is also a "cross-field" category to recognize the top $1 \%$ of multidisciplinary reviewers performing across multiple ESI research areas.

Our sample consists of the Top 1\% Reviewers in 2018 and 2019 in each of the 22 fields plus the cross-field category. The data was gathered through Publons' API from January 26, 2020, to January 29, 2020. In 2018, Top 1\% awards were given to 6,050 reviewers in 2018 and to 4,621 in 2019. After de-duplicating, the final data set contained 8,173 reviewers.

Each reviewer has a profile listing their publications and review metrics. Before the posted information is made public, it must be confirmed by the corresponding reviewers or the journal's editors via email and verified by Publons. ${ }^{3}$ We used three of the profile indicators as measures of reviewing activity: the number of reviews conducted (\#Reviews); the number of journals the reviewer has contributed to (\#Journals); and the average number of words per review (\#Length). Admittedly, the average number of words for reviewers is a weak indicator of reviewing quality, as highlighted in the 2018 Global State of Peer Review (Clarivate Analytics, 2018, p. 36), but we find it a useful indicator to represent reviewing efforts.

\footnotetext{
2 See https://publons.com/community/awards/awards-categories-2018/, $\quad$ https://publons.com/awards/peerreview/2019/methodology/

3 https://publons.freshdesk.com/support/solutions/articles/12000062033-how-do-i-add-peer-reviews-to-publons-
} 
We use the number of publications to represent the research activity of reviewers. Publons was acquired by Clarivate Analytics in 2017 and, subsequently, each user also has a research profile on Publons populated by data drawn from Web of Science (WoS) via a unique Clarivate-wide Researcher ID. Accordingly, there are two ways to obtain the lists of reviewers' publications, either by retrieving the publication list from the reviewer's Publons homepage or by using Researcher IDs to retrieve and download bibliographic information directly from WoS. When comparing the record of publications retrieved from the reviewer's Publons homepage and the record downloaded from WoS through Researcher ID, as many as 76\% of the reviewers had an equal or greater number of publications listed in WoS than in Publons. Hence, as we found Publons's publication lists to be generally incomplete, we chose to download all publication data directly from WoS using the Researcher ID as our search criteria. The WoS uses its proprietary algorithms to develop Researcher ID, which have been successfully used to study researchers (Bornmann \& Williams, 2017; Huang et al., 2020; Liu et al., 2018). We gathered the publication data through WoS from February 17, 2020, to February 28, 2020. Some reviewers' Researcher IDs have no download records. In these cases, we conducted a supplementary search of publications using ORCID as an alternative identifier ${ }^{4}$ and added any data found to the set. ${ }^{5}$ Publications were checked to identify the reviewers' institutions and research areas with the publications' institutions and research areas. Those that did not match correctly were removed. ${ }^{6}$ The remaining publications were then simply counted (\#Publications) as the final indicator of research activity.

Given that this measure of research activity is dependent on the length of a researcher's career, we also included an "academic experience" variable, calculated as the difference between 2020 and the year of first publication.

One step in our gender analysis includes a comparison of gender representation in reviewing and gender representation in research activity in general. For this purpose, statistics about gender representation in different areas of research have been collected from The Researcher Journey Through a Gender Lens report (Elsevier, 2020), from Eigenfactor.org ${ }^{7}$ based on JSTOR 1990-2011(West et al., 2013), and from a series of studies of gender representation in scientific publishing that we will refer to below.

\section{Data processing}

We determined the gender of reviewers using a combination of several methods, as shown in Fig. 2. For practical reasons, the identification of nonbinary and transgender reviewers is

\footnotetext{
${ }^{4}$ https://orcid.org/

5 There are 317 reviewers' Researcher IDs with no retrieval records in WoS. 206 out of 317 reviewers have the ORCID. Since the search results for Researcher ID and ORCID are verified to be consistent in WoS, we use the ORCID of 206 reviewers to obtain supplementary publication data.

${ }^{6}$ We calculated the reviewer's academic experience based on the year of the first publication. Among all reviewers, 26 reviewers' have more than 60 years of experience ( 7 of them are even more than 90 years), which is abnormal in practice. Therefore, publications of these 26 reviewers are manually checked and the ones do not belong to the corresponding reviewers are removed.

7 http://eigenfactor.org/projects/gender/\#
} 
difficult. Therefore, like other studies, this study also assigns gender as binary (Débarre et al., 2018; Fox et al., 2017; Fox et al., 2018).

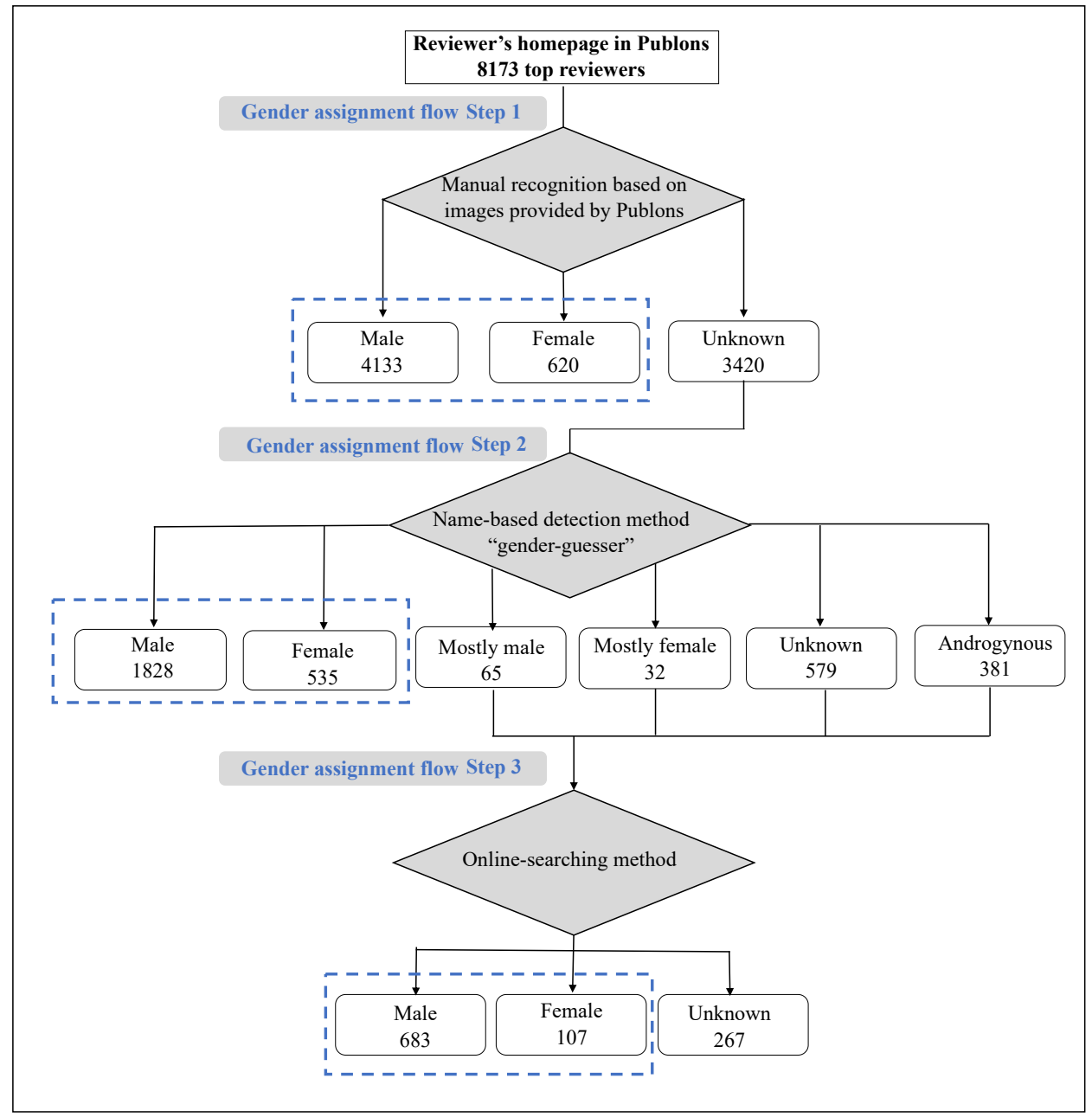

Figure 2. Gender assignment methods and procedures

First, we looked for a profile photo. If one existed, and the gender was unambiguous, it was recorded. There are already some studies that have identified the researchers' gender from their website photograph (O'Connor et al., 2018; Zeng et al., 2016). Based on users' photograph, face recognition algorithms also have become a widespread tool for inferring the gender (Karimi et al., 2016). Next, we applied a name-based method. Many studies have shown that a person's first name can be a strong signal of their gender (Liu \& Ruths, 2013). Python 4.0's gender-guesser package ${ }^{8}$ contains over 45,000 names with gender assignments of "unknown" (name not found), "andy" (androgynous), "male", "female", "mostly_male", and "mostly_female". The strength of this tool is that gender assignments are checked manually by natives of different countries. The approximate frequencies of the category assignments are provided on a per-country basis, which can be used to screen the results for further sorting. Santamaría \& Mihaljević's (2018) work compared five name-to-gender inference services. The result has shown that gender-guesser achieved the lowest misclassification rate without

\footnotetext{
${ }^{8}$ See https://pypi.python.org/pypi/gender-guesser/
} 
parameter tuning. Gender-guesser has been widely used in scientometric studies (Adler et al., 2020; Feramisco et al., 2009) and has been proved to have relatively high accuracy (Knowles et al., 2016; Zeina et al., 2020) $)^{9}$. In our sample, gender-guesser marked 5,519 of the 8,173 reviewers as definitively male or female. We corroborated this result with Namsor ${ }^{10}$, another name-based gender classifier that also predicts the likely cultural origin of the name. The overlap ratio was $98.5 \%$. For the remaining reviewers, we conducted a manual search of pertinent online pages such as institutional profiles and directories, ResearchGate, Google Scholar, etc., for profile photos, honorifics (Mr., Mrs., etc.), or pronouns (he, she, etc.). The gender of 7,906 reviewers was identified through one or more of these methods. Removing 267 reviewers of indeterminate gender as well as 1,784 reviewers without a Researcher ID, we arrived at a final research sample of 6,289 reviewers, accounting for 77\% of Publons" "Top 1\% Reviewers" and consisting of 5,406 males (86\%) and 883 females (14\%). This unbalanced ratio is in line with previous studies showing that male researchers are more likely to be suggested as reviewers (75\%-85\%), leading to fewer female reviewers overall (Fox et al., 2016; Fox et al., 2017).

Research field assignments were taken from Publon's field assignment of the reviewer (ESI classification), noting that that the most active reviewers can be assign to multiple research fields. Geographic affiliations were determined from the country information in Publons' awards lists or, where missing, the ORCID platform. This method was not completely successful as we could only allocate 5,533 of the 6,289 reviewers to a country. However, this information is not essential to the entire analysis, so these reviewers were simply left out in the analysis based on geographic region.

\section{Results}

\section{Differences by country, research field and academic experience}

The persistent phenomenon of female underrepresentation in academia was also seen in this study. The results of the specific analyses by country, research field, and academic experience are as follows.

\section{By country}

Gender difference is a pervasive phenomenon in all levels and fields. At the national level, the more economically developed a country is, the more equal opportunities it has for both males and females in many areas (Jayachandran, 2015). In academia, economically developed regions tend to have more female researchers (Elsevier, 2017). We investigated whether these differences are also present in the group of reviewers. Our first analysis was to divide the

\footnotetext{
9 As shown in Fig 2, we already manually marked 4753 reviewers with male or female based on their images provided by Publons. We further applied gender-guesser to assign gender based on the name of these reviewers. The overlap ratio was $67.52 \%$ (3209) and the share of misclassification is $2.38 \%$ (113). There are $8.02 \%$ (381) names responded with "andy" and $22.09 \%$ (1050) names responded with "unknown".

${ }^{10}$ Namsor (https://www.namsor.com/) This tool was used in Elsevier's report The Researcher Journey Through a Gender Lens (2020).
} 
countries into the four levels of the UNDP's 2019 Human Development Index (HDI), i.e., very high, high, medium, and low (United Nations Development Program, 2019). The HDI measures a country's average achievements across the basic elements of human development, such as quality of health, education, and standard of living.

As the results of our analysis in Table 1 show, there is a clear gap in the distribution of reviewers for all four categories. Very few originate from low or medium HDI countries, with almost all concentrated in very high HDI countries, especially the West, and the gap widens as the level of development decreases.

Table 1. The number and proportion of reviewers by level of human development

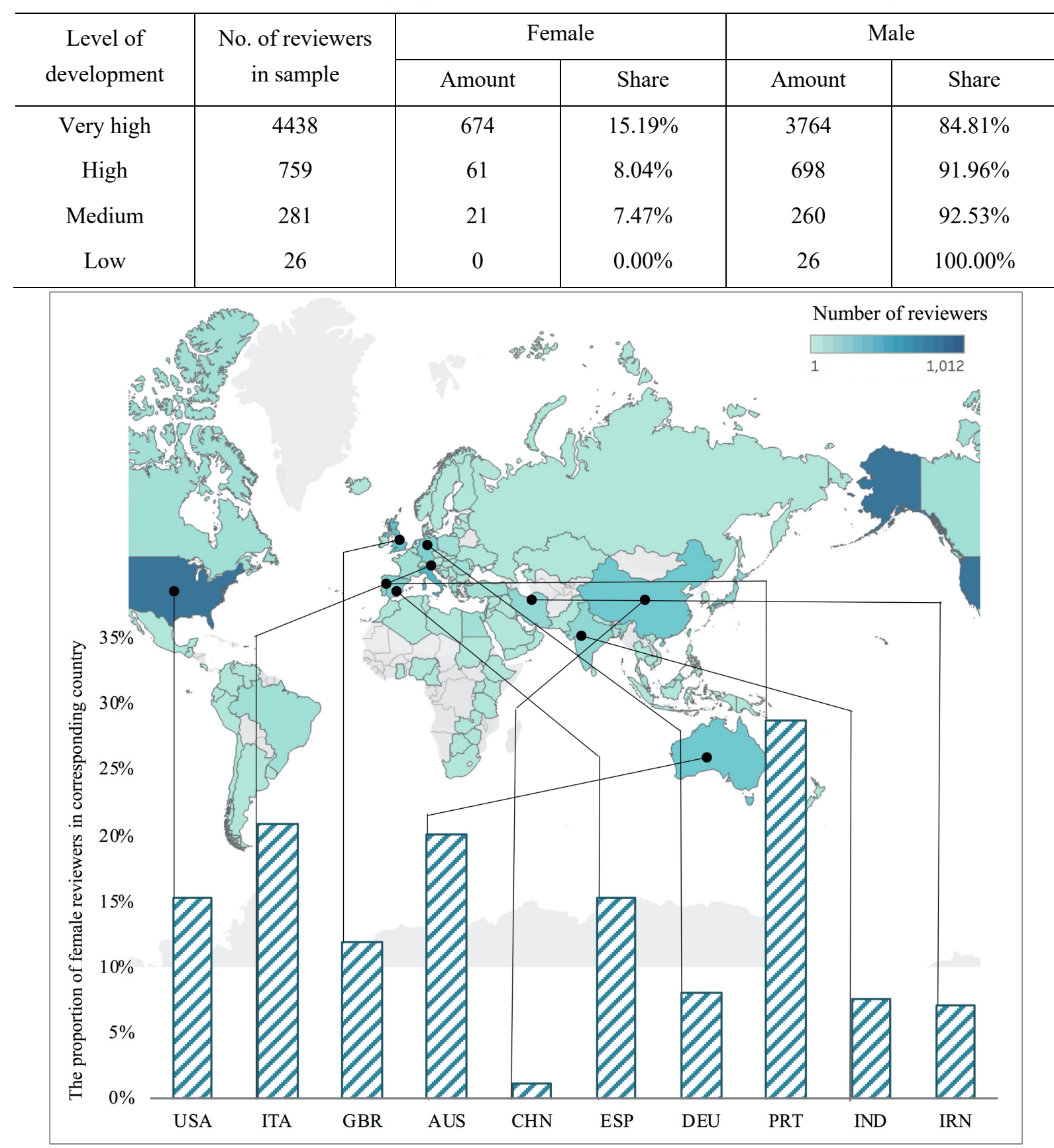

Figure 3. The proportion of female reviewers in the ten countries with the most reviewers 
Fig. 3 presents the number of reviewers in the ten countries with the largest numbers of reviewers. The shading of each country in the map indicates the contribution of its reviewers. The height of the column reflects the proportion of female reviewers. The United States has the most reviewers $(1012,18.3 \%)$ at 2.3 times that of second-ranked Italy $(440,7.9 \%)$. The proportion of female reviewers varies but all are drastically imbalanced. The World Economic Forum's Global gender gap report 2020 notes that Western Europe has the smallest gender gap, followed by North America (World Economic Forum, 2020). We see a similar pattern in our distribution. In countries like Portugal (28.7\%) and Italy (20.9\%), women account for a relatively high proportion of reviewers, whereas many Asian countries fail to even reach 10\%. Overall, countries with high HDIs have a higher proportion of female reviewers, albeit still at far lower numbers than men.

By field of research

As we now turn to an analysis by field of research of gender representation among active reviewers, we will compare the results to available statistics on gender representation in scientific publishing in general in the same fields of research. Statistics for comparing the proportions of active female reviewers to the proportions of female researchers that are active as authors in different areas of research have been collected from The Researcher Journey Through a Gender Lens report (Elsevier, 2020), from Eigenfactor.org based on JSTOR 19902011(West et al., 2013), and from a series of studies of gender representation in scientific publishing that we will refer to below. Elsevier's report provides the number and percent of men and women among active authors in 15 countries (Argentina, Brazil, Mexico, Canada, USA, UK, Portugal, Spain, France, Italy, Netherlands, Germany, Denmark, Australia, Japan) and among the EU28 overall and in each subject area during the periods 2014-2018. However, there are no statistics on the number and percent of active male and female authors in each subject area for all the countries covered. Therefore, we conducted country-level aggregations and calculations based on the data provided by Elsevier, which ultimately allowed us to obtain the percent of female authors in each subject field (Table A1 in the Appendix). Although Elsevier's classification of subject areas is different from that of Publons, the subject classifications are similar enough to be useful. Therefore, the proportions of female reviewers by field are compared to the statistics of Elsevier's report.

Table 2 shows the gender distribution of reviewers across research fields. The degree of gender difference varies but, as expected, every field has a predominance of male reviewers. However, there were some noteworthy observations:

- Science, Technology, Engineering, and Mathematics fields (STEM) tend to have a significant minority of female reviewers, with proportions lower than $10 \%$ in Computer Science, Engineering, Geosciences, Materials Sciences, Mathematics, Physics, and Space Science. Similarly, there are also fewer female researchers in such fields. The statistics of active authors during the periods 2014-2018 have shown that Mathematics, 
Engineering, Energy, Computer Science, Physics and Astronomy, Materials Science are the several subject areas with the lowest share of females (Elsevier, 2020, pp.158-159) (Appendix, Table A1). This also corresponds to a series of studies that have reflected female researchers' general low presence and performance in STEM fields (Arruda et al., 2009; Burke \& Mattis, 2007; Ghiasi et al., 2015; Holman et al., 2018; MihaljevićBrandt et al., 2016).

- The proportions of female reviewers are relatively higher in the multidisciplinary and cross-field categories (both around 11\%) than in some STEM fields. A scientometric study has shown that the share of women in highly cited researchers in cross-field research is $14.55 \%$, which is higher than in the main categories (10.97\%) (Shamsi, 2020). A study found that women outperform men in multitasking paradigms (Stoet et al., 2013). Multitasking and task switching on activities may be helpful for explaining the performance of females in multidisciplinary and cross-field categories.

- Social Sciences had the most significant number and proportion of female reviewers of all the fields at $25.18 \%$. Elsevier's report has shown that the share of women among active authors in Social Sciences is close to half (45.08\%) (Elsevier, 2020, pp158-159) (Appendix, Table A1). The statistics from JSTOR also reflected a relatively higher proportion of female authors in some social science disciplines during 1990-2011, such as Sociology (41.4\%) and Education (46.3\%) (West et al., 2013).

- The health sciences also had higher than average female representation among active reviewers, including Psychiatry and Psychology (24.46\%), Immunology (22.78\%), and Neuroscience and Behavior (17.5\%). In Elsevier's statistics of active authors during the periods 2014-2018, Psychology (57.49\%), Immunology and Microbiology (48.42\%), Neuroscience (46.21\%) also had higher percentages of female authors, which rank as the top five among all subject areas (Elsevier, 2020, pp158-159) (Appendix, Table A1). In the above analyses we have seen that although there are differences in the proportions of female reviewers and female authors/researchers, there is some consistency in the rankings of fields based on the proportions. 
Table 2. The proportions of male and female reviewers in research fields ${ }^{11}$

\begin{tabular}{c|c|c|c|c|c|c|c}
\hline Rank & Research fields & Female & Male & Rank & Research fields & Female & Male \\
\hline 1 & Social Sciences & $25.18 \%$ & $74.82 \%$ & 13 & Chemistry & $11.58 \%$ & $88.42 \%$ \\
2 & Psychiatry and Psychology & $24.46 \%$ & $75.54 \%$ & 14 & Clinical Medicine & $11.52 \%$ & $88.48 \%$ \\
3 & Immunology & $22.78 \%$ & $77.22 \%$ & 15 & Multidisciplinary & $11.21 \%$ & $88.79 \%$ \\
4 & Agricultural Sciences & $20.08 \%$ & $79.92 \%$ & 16 & Cross-Field & $10.88 \%$ & $89.12 \%$ \\
5 & Environment and Ecology & $19.16 \%$ & $80.84 \%$ & 17 & Computer Science & $9.00 \%$ & $91.00 \%$ \\
6 & Neuroscience and Behavior & $17.50 \%$ & $82.50 \%$ & 18 & Materials Science & $8.55 \%$ & $91.45 \%$ \\
7 & Microbiology & $17.02 \%$ & $82.98 \%$ & 19 & Engineering & $6.50 \%$ & $93.50 \%$ \\
8 & Economics and Business & $15.92 \%$ & $84.08 \%$ & 20 & Mathematics & $5.56 \%$ & $94.44 \%$ \\
9 & Molecular Biology and Genetics & $15.15 \%$ & $84.85 \%$ & 21 & Geosciences & $4.91 \%$ & $95.09 \%$ \\
10 & Pharmacology and Toxicology & $15.10 \%$ & $84.90 \%$ & 22 & Physics & $4.00 \%$ & $96.00 \%$ \\
11 & Biology and Biochemistry & $13.99 \%$ & $86.01 \%$ & 23 & Space Science & $0.00 \%$ & $100.00 \%$ \\
12 & Plant and Animal Science & $11.86 \%$ & $88.14 \%$ & & & \\
\hline
\end{tabular}

By academic experience

Experience indicates the longevity of an author's active engagement in a field of research (Milojević, 2012). As shown in Table 3, most of the reviewers had less than 20 years' experience. Notably, the proportion of female reviewers decreases with more longevity, all but disappearing after 20 years. One possible explanation may be that the proportion of females in research is lower in the older generations (Sivertsen, 2018). This reflects the gradual disappearance of women from academic, which is used as a metaphor for leaky pipeline (Wickware, 1997). The metaphor of the leaky pipeline seems to be applicable to academic reviewers as well.

Table 3. The number and proportion of reviewers by academic experience

\begin{tabular}{c|c|c|c|c|c}
\hline \multirow{2}{*}{$\begin{array}{c}\text { Academic } \\
\text { experience (Year) }\end{array}$} & \multirow{2}{*}{$\begin{array}{c}\text { No. of reviewers } \\
\text { in sample }\end{array}$} & \multicolumn{2}{|c|}{ Female } & \multicolumn{2}{c}{ Male } \\
\cline { 3 - 6 } & 2104 & 298 & $14.16 \%$ & 1806 & $85.84 \%$ \\
\hline 10 & 2431 & 352 & $14.48 \%$ & 2079 & $85.52 \%$ \\
$11 \sim 20$ & 985 & 140 & $14.21 \%$ & 845 & $85.79 \%$ \\
$21-30$ & 389 & 40 & $10.28 \%$ & 349 & $89.72 \%$ \\
$31 \sim 40$ & 163 & 8 & $4.91 \%$ & 155 & $95.09 \%$ \\
$>40$ & 6072 & 838 & $13.80 \%$ & 5234 & $86.20 \%$ \\
Total & & & & &
\end{tabular}

\section{Differences in reviewing activity}

Number of reviews

The number of reviews can be used to reflect the reviewers' degree of participation in reviewing activities. In general, the higher the number of reviews, the more reviewing activities that reviewers are involved in. Fig. 4 charts the gender gaps in the number of reviews. Fig. 4(a)

\footnotetext{
11 The research fields are ordered by the proportion of female reviewers.
} 
shows that male reviewers have a significantly higher average number of reviews than female reviewers. Fig. 4(b) illustrates the relationship between the average number of reviews and the proportion of male and female reviewers. As the number of reviews increases, the proportion of male reviewers increases as well, whereas the opposite holds for female reviewers. This may reflect that male reviewers are more active in reviewing activities than female reviewers.

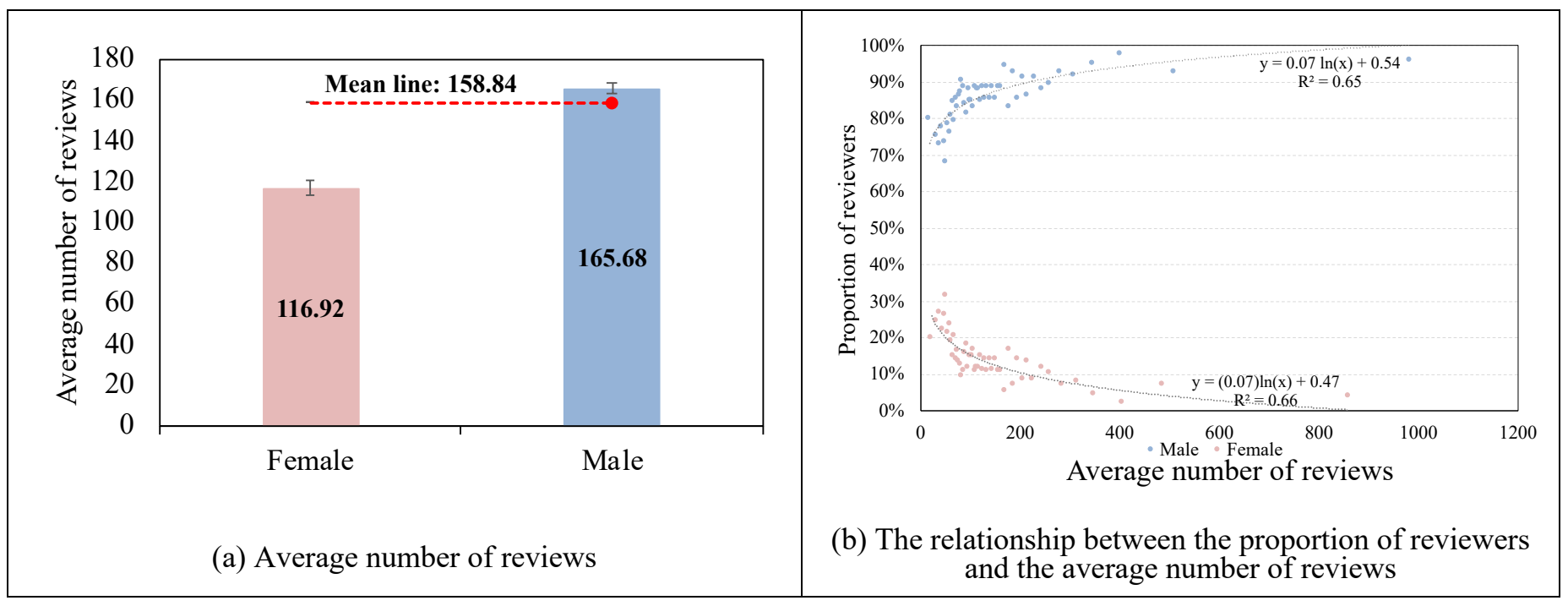

Figure 4. Differences in the average number of reviews

We further explore the gender differences in the number of reviews by different academic experience groups, as shown in Fig. 5. In general, the number of reviews increases with academic experience for both male and female reviewers, especially in their early career (the academic experience groups of $\leqslant 10$ and 11-20). Contrary to expectations, the increase in number of reviews almost comes to a halt with the rising of academic experience in the later career stage of reviewers (the academic experience groups of 21-30 and 31-40). Note that the number of female reviewers in the academic experience group of $>40$ is too small (only 8) to be representative, as mentioned in Table 3. From the gender perspective, the increasing trend in the number of reviews for male reviewers is more apparent overall compared to that for female reviewers.

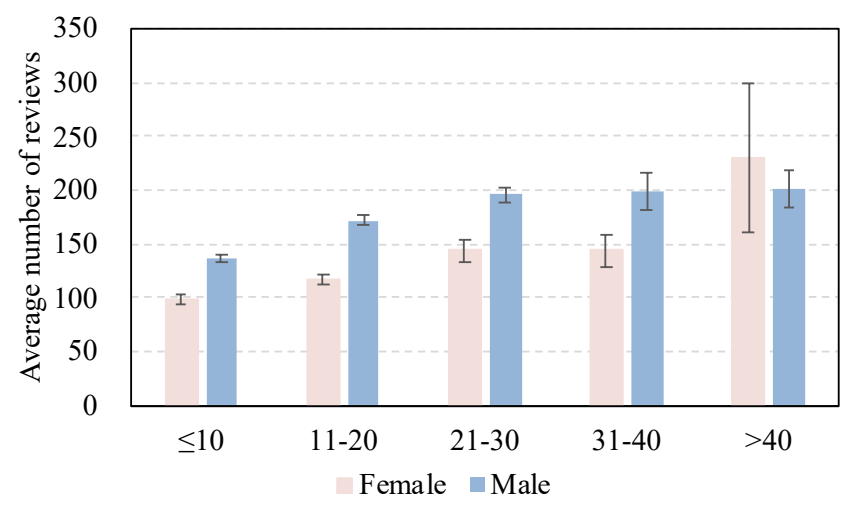

Figure 5. Average number of reviews in different academic experience groups 


\section{Number of journals}

The number of journals a reviewer contributes to reflects the broadness of the reviewing activity. Fig. 6(a) reflects the gender gaps in the average number of journals that men and women review for. With men reviewing for an average of 33 different journals over their career, compared to 27 for women, the difference is not large. However, from Fig. 6(b), the proportion of female reviewers decreases as the average number of journals increases, whereas the opposite is true for male reviewers. Men generally seem to be broader in their reviewing activities but, of course, the potential to do so is also dependent on the frequency of reviews.

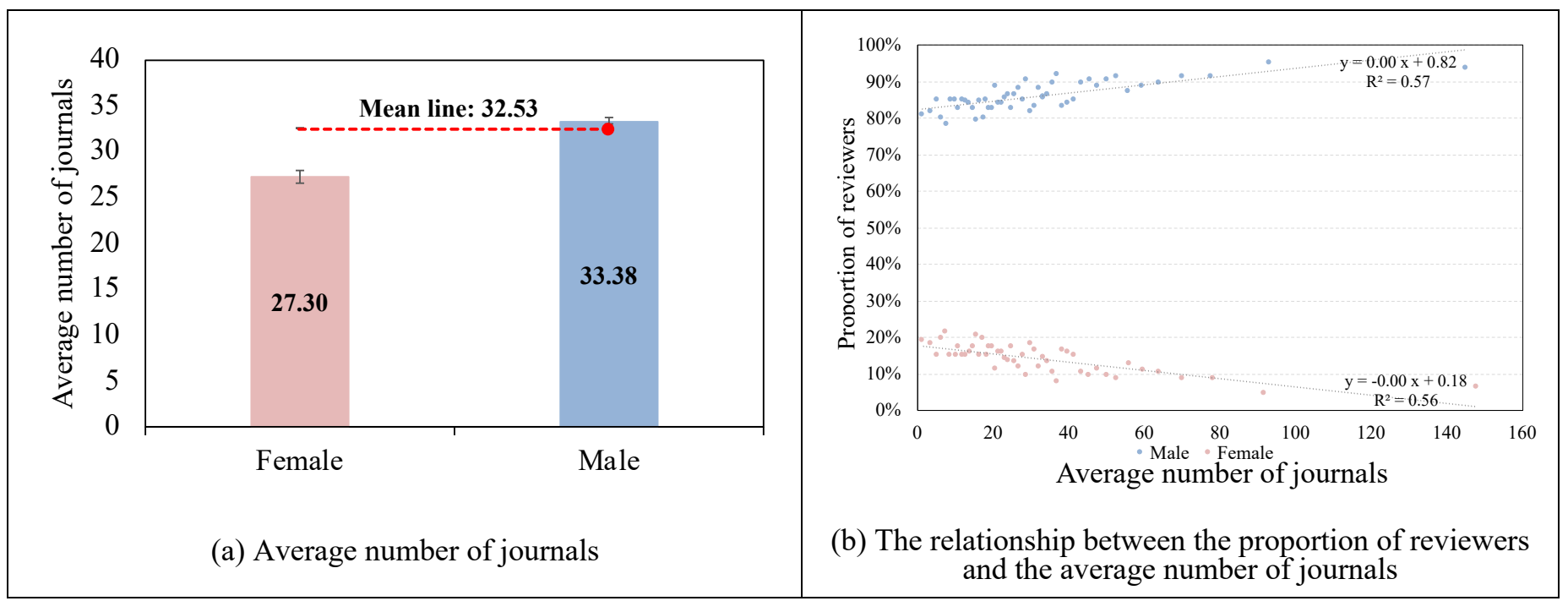

Figure 6. Gender differences in the average number of journals

The gender differences in the number of journals by different academic experience groups are similar to those seen in the number of reviews. The number of journals is higher for males than females in each academic experience group. Overall, the number of journals increases significantly for junior reviewers (the academic experience groups of $\leqslant 10$ and 11-20), while the number of journals are relatively constant for senior reviewers (the academic experience groups of 21-30 and 31-40).

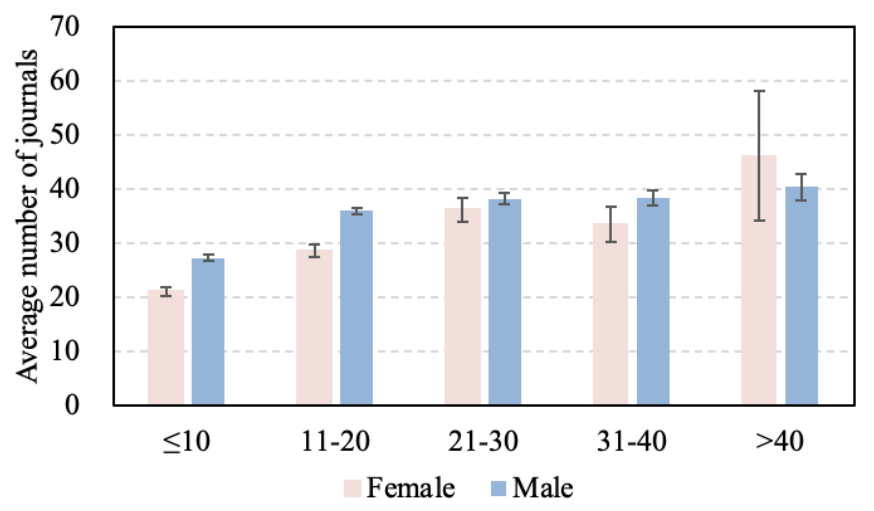

Figure 7. Average number of journals in different academic experience groups 


\section{Length of reviews}

Currently, there are no uniform indicators to measure the quality of reviews. However, there are some indirect indicators that can be used as weak proxies. For example, a longer review may indicate more careful and specific comments and, therefore, more efforts to provide a higher quality review. The length of reviews is measured by the average number of words in the review. As Fig. 8(a) shows, the average number of words per review is clearly higher for females. Interestingly, there is a slight decrease in the proportion of male reviewers as the average number of words increases.

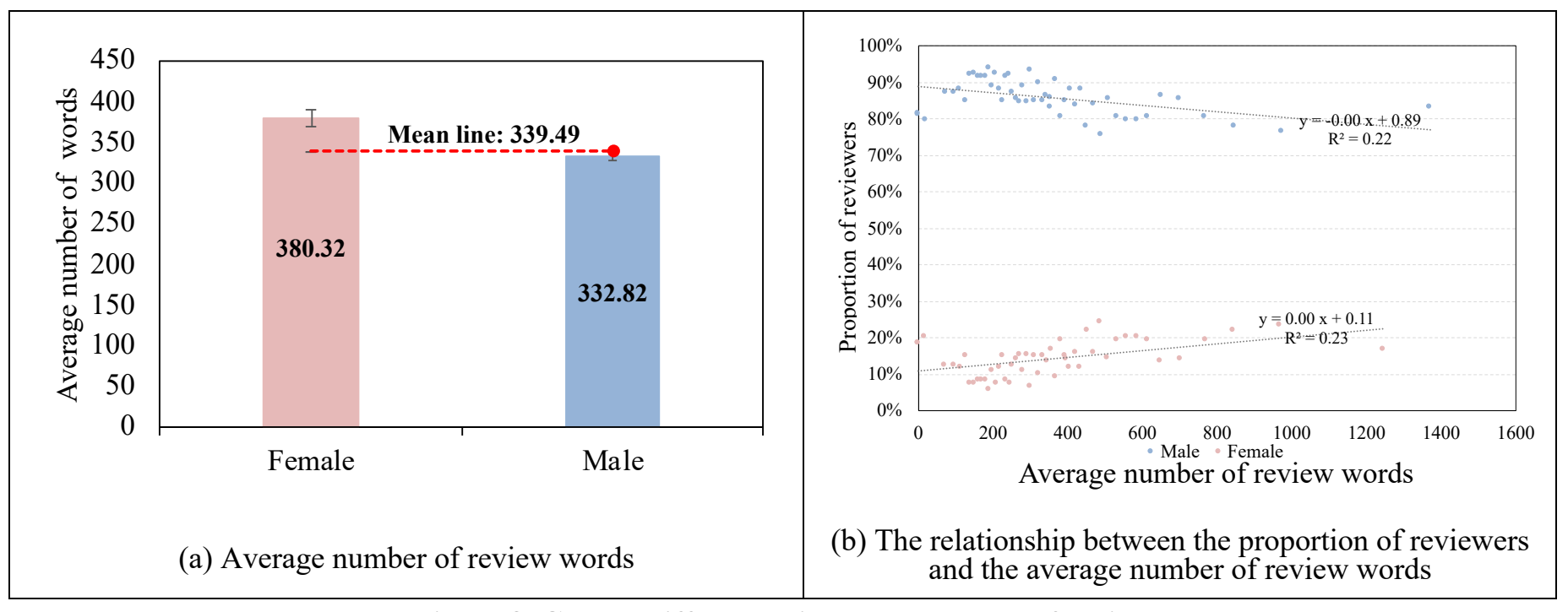

Figure 8. Gender differences in average length of review

(Note: This analysis excludes 358 reviewers due to lack of information about the length of their reviews.)

Unlike the number of reviews and journals in different academic experience groups, the average length of reviews does not change significantly with the accumulation of academic experience (Fig 9). One possible explanation for these results is that reviewers usually have their own reviewing styles which do not easily change throughout their careers. Reviewers with relatively mature experience write longer reviews (the academic experience group of 31-40). The average number of review words by reviewers in their early career stage (the academic experience group of $\leqslant 10$ ) are almost at the same level as for reviewers in later career stages, indicating that young reviewers may also provide content-rich reviews. From the gender perspective, the average length of reviews for female reviewers is clearly longer than for male reviewers in almost all academic experience groups (except in the academic experience group of $>40$ ). 


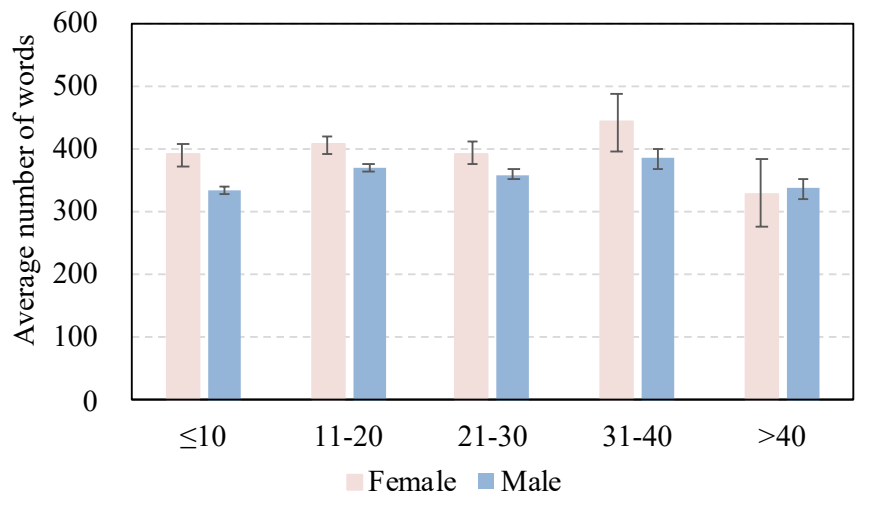

Figure 9. Average number of review words in different academic experience groups

\section{Correlations between reviewing and research activity}

\section{Research activity}

Our sample contains the Top $1 \%$ of reviewers in terms of reviewing output. However, reviewers are also researchers, which raises the question of whether gender differences can also be observed in these reviewers' research activities. Furthermore, we intend to investigate the correlation between reviewers' reviewing activity and research activity.

Beginning with a base picture of research activity in general, we know from the literature that, generally, research activity is judged by publication metrics (Cameron et al., 2013). The number of publications is a standard indicator of academic productivity. Numerous studies have shown that female researchers tend to publish significantly fewer publications than their male colleagues (Abramo et al., 2009; Cole \& Zuckerman, 1984; Huang et al., 2020). This difference is also reflected in our sample, as illustrated in Fig. 10(a). The average number of research publications by male reviewers is significantly higher than for female reviewers, and Fig. 10(b) shows a slightly increasing trend in the proportion of male reviewers as the average increases. This indicates that the widespread gender differences in academic productivity also occur in our sample of reviewers.

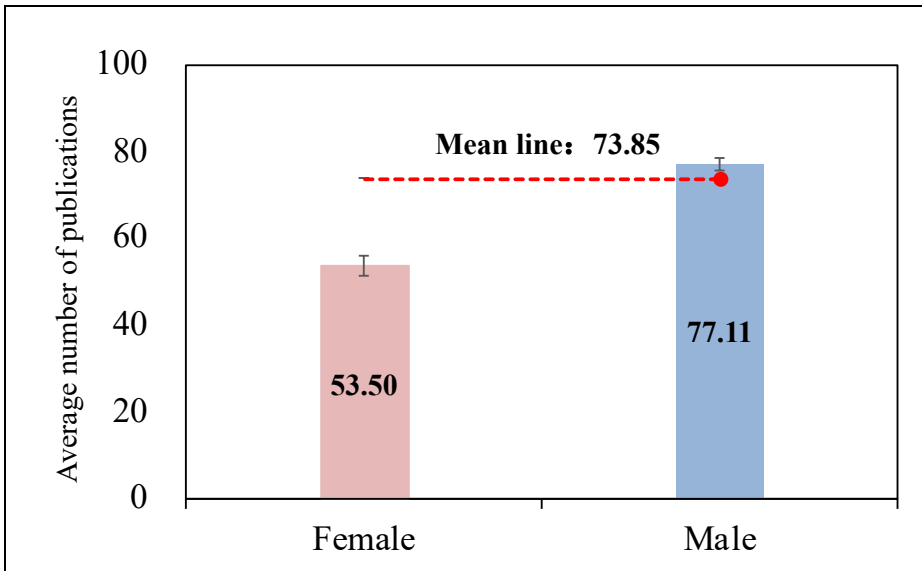

(a) Average number of publications

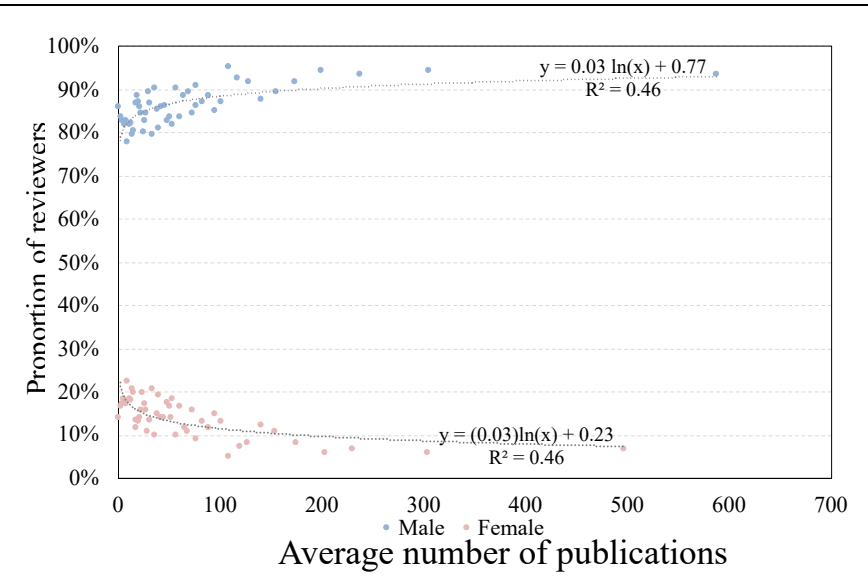

(b) The relationship between the proportion of reviewers and the average number of publications 


\section{Figure 10. Gender differences in the average number of publications}

(Note: The 317 reviewers lacking publication information are excluded.)

As for the academic productivity by different academic experience groups, a significant increase in the number of publications is observed with the higher accumulation of experience (Fig 11). As a striking exception, the gender difference in the number of publications is almost absent in the early career stage of reviewers (the academic experience group of $\leqslant 10$ ). However, the difference in academic productivity between males and females in the later stages of their careers is remarkable, which also indicates the leaky pipeline in females' careers in terms of productivity. As reflected in previous studies, manuscripts with female authors obtain lower peer-review scores and have lower probabilities of positive editorial decisions than manuscripts with male authors (Fox \& Paine, 2019; Murray et al., 2019). In a longer time span, this may influence females' academic productivity. The low academic productivity of females may have a negative effect on their academic rank, on the opportunity for research collaborations, and on the likelihood of being awarded funding. In turn, these factors may affect academic productivity and reinforce the vicious circle for females.

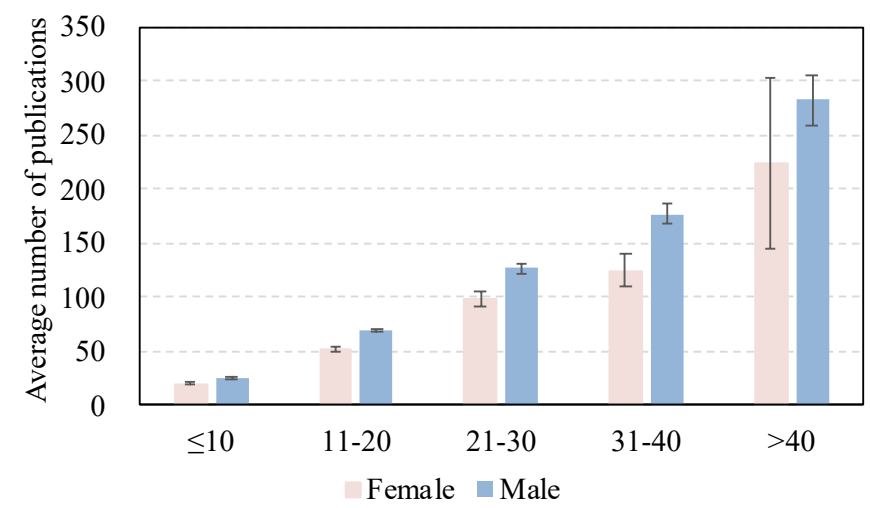

Figure 11. Average number of publications in different academic experience groups

\section{Correlation analysis}

The next step in our research was to focus on the relationship between reviewing activity and research activity. We wanted to know to what degree active reviewers are active researchers as well. We used Spearman's correlation coefficient with Bonferroni correction to analyze the relationship between reviewing activity and research activity. Spearman's correlations were used because the data for the variables did not conform to a normal distribution. The statistical analysis was performed with STATA 15.1. Table 4 illustrates the Spearman correlation coefficients for \#Reviews, \#Journals, and \#Length versus \#Publications. On the whole, research activity, as reflected by the number of publications, has a weak correlation with reviewing activity. There is a clearer relationship between productivity and the number of journals receiving reviews than between productivity and the number of reviews. We found that there was little or almost no relation between the number of publications and the length of review. Additionally, within the reviewing activity alone, the relationship between the number of reviews and the number of journals was significant. 
Moreover, none of the differences by gender were significant. In terms of reviewing activity, the correlation coefficient between the number of reviews and journals by female reviewers was higher than that of male reviewers (female: $\rho=0.71, p<0.01$; male: $\rho=0.69, p<0.01$ ), and the general correlation between reviewing activity and research activity was weak for both genders. However, female reviewers had a slightly higher correlation between academic productivity (\#Publications) and review diversity (\#Reviews plus \#Journals).

Table 4. Spearman's correlation matrix between reviewing activity and research activity

\begin{tabular}{|c|c|c|c|c|}
\hline \multicolumn{5}{|c|}{ All active reviewers } \\
\hline & Reviews & Journals & Length & Publications \\
\hline Reviews & 1 & & & \\
\hline Journals & $0.70 * * *$ & 1 & & \\
\hline Length & $-0.04 * * *$ & $0.11 * * *$ & 1 & \\
\hline Publications & $0.38 * * *$ & $0.42 * * *$ & $0.04 * *$ & 1 \\
\hline \multicolumn{5}{|c|}{ Male active reviewers } \\
\hline & Reviews & Journals & Length & Publications \\
\hline Reviews & 1 & & & \\
\hline Journals & $0.69 * * *$ & 1 & & \\
\hline Length & $-0.04 *$ & $0.12 * * *$ & 1 & \\
\hline Publications & $0.36^{* * *}$ & $0.40 * * *$ & $0.04 * *$ & 1 \\
\hline \multicolumn{5}{|c|}{ Female active reviewers } \\
\hline & Reviews & Journals & Length & Publications \\
\hline Reviews & 1 & & & \\
\hline Journals & $0.71 * * *$ & 1 & & \\
\hline Length & 0 & $0.14 * * *$ & 1 & \\
\hline Publications & $0.44 * * *$ & $0.50 * * *$ & 0.05 & 1 \\
\hline
\end{tabular}

(Note: This analysis only includes the 5,731 reviewers with complete data on all four indicators of \#Reviews, \#Journals, \#Length, \#Publications)

\section{Gender differences in reviewing and research activities across different research fields}

Breaking down the correlations between reviewing and research activity into research fields revealed some insights into gender differences in addition to those discussed in the analysis of reviewing activity alone. Figs. $12-15$ present each indicator's mean value by field of research. "Gender gap" refers to the average value of different indicators for male reviewers minus that for female reviewers. It is important to note that there are some research fields where the number of female reviewers is too small to provide statistical significance. Therefore, in Figs. $12-15$, asterisks $(*)$ are added to the names of research fields with less than $10 \%$ female representation to mark the specificity of the results. Additionally, in Figs. 12-15, the red line 
represents the overall mean value of male/female reviewers under all research fields in corresponding indicators.

In terms of reviewing activities, both the average number of reviews (Fig. 14) and journals (Fig. 15) are higher for males than for females in all fields of research. Extreme cases of small or large gender gaps tend to occur in STEM and bio-medical fields. Consistent with the general analysis is also that the average length of reviews is clearly higher among female reviewers (Fig. 16). For example, Economics and Business has the highest average number of words per review, with women topping an average of almost 699 words over 566 for men. It is also worth noting that female reviewers write longer reviews than males in fields such as Physics, Engineering, and Materials Science where the proportion of female reviewers is generally low. Female reviewers in these fields clearly dedicate more efforts, which is worthy of attention.

Many studies have confirmed the gender imbalance in academia (Larivière et al., 2013; Holman et al., 2018). Females may be more likely to value opportunities to advance their careers in a professional environment that is not conducive to female's advancement. Research on female engineers has found that females are equally or more influential than their male peers across fields where they are least represented (Ghiasi et al., 2015). This may suggest a selection effect: only extremely qualified and accomplished females can stay in the field. Therefore, females might need to put more effort and work harder to access the same resources as their male peers. One possible effort is participation in reviewing activity. This may partially explain why female reviewers are not inferior to males in some fields with few female reviewers.

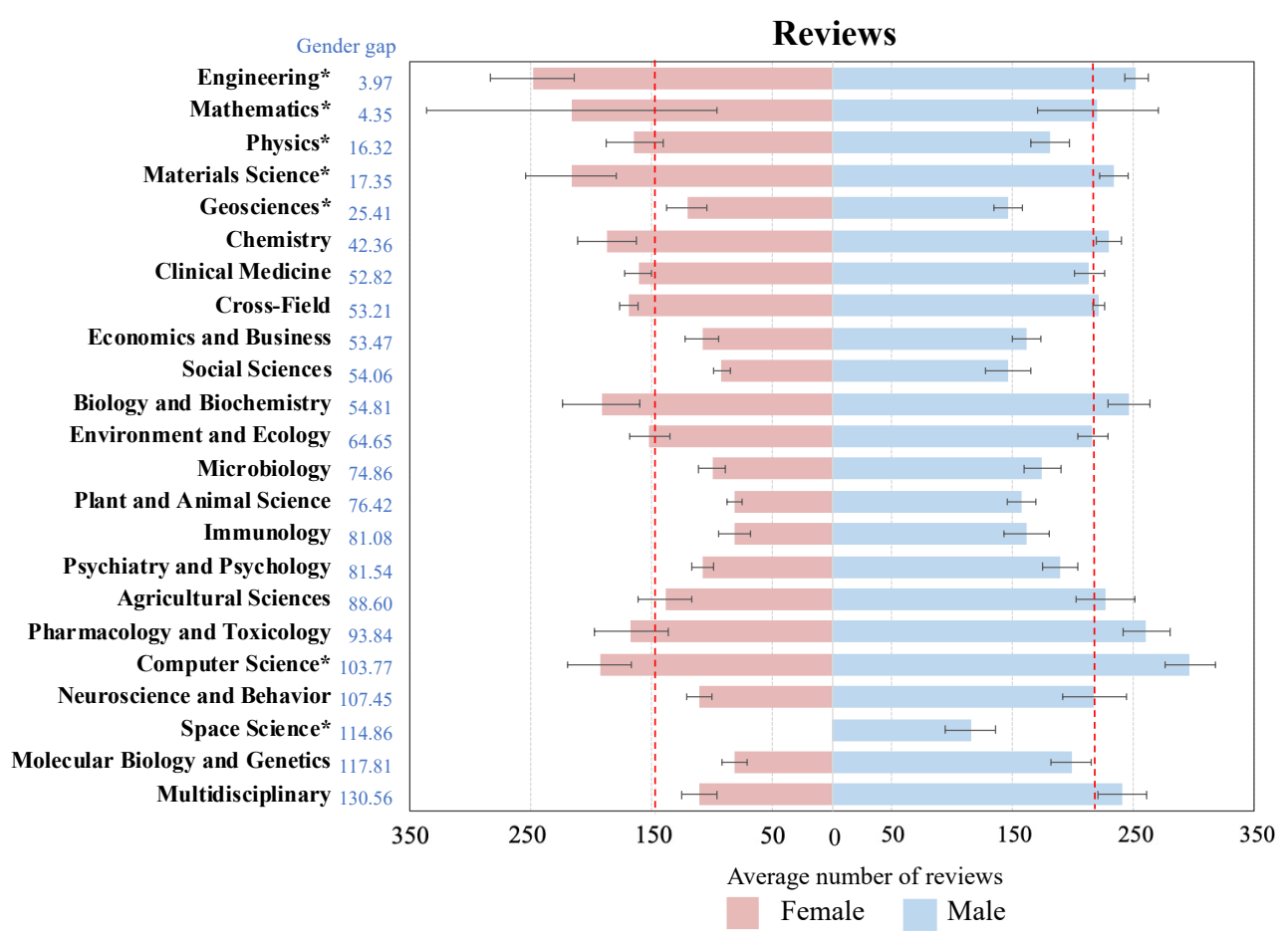

Figure 12. Average number of reviews by field of research and gender (\#Reviews) 


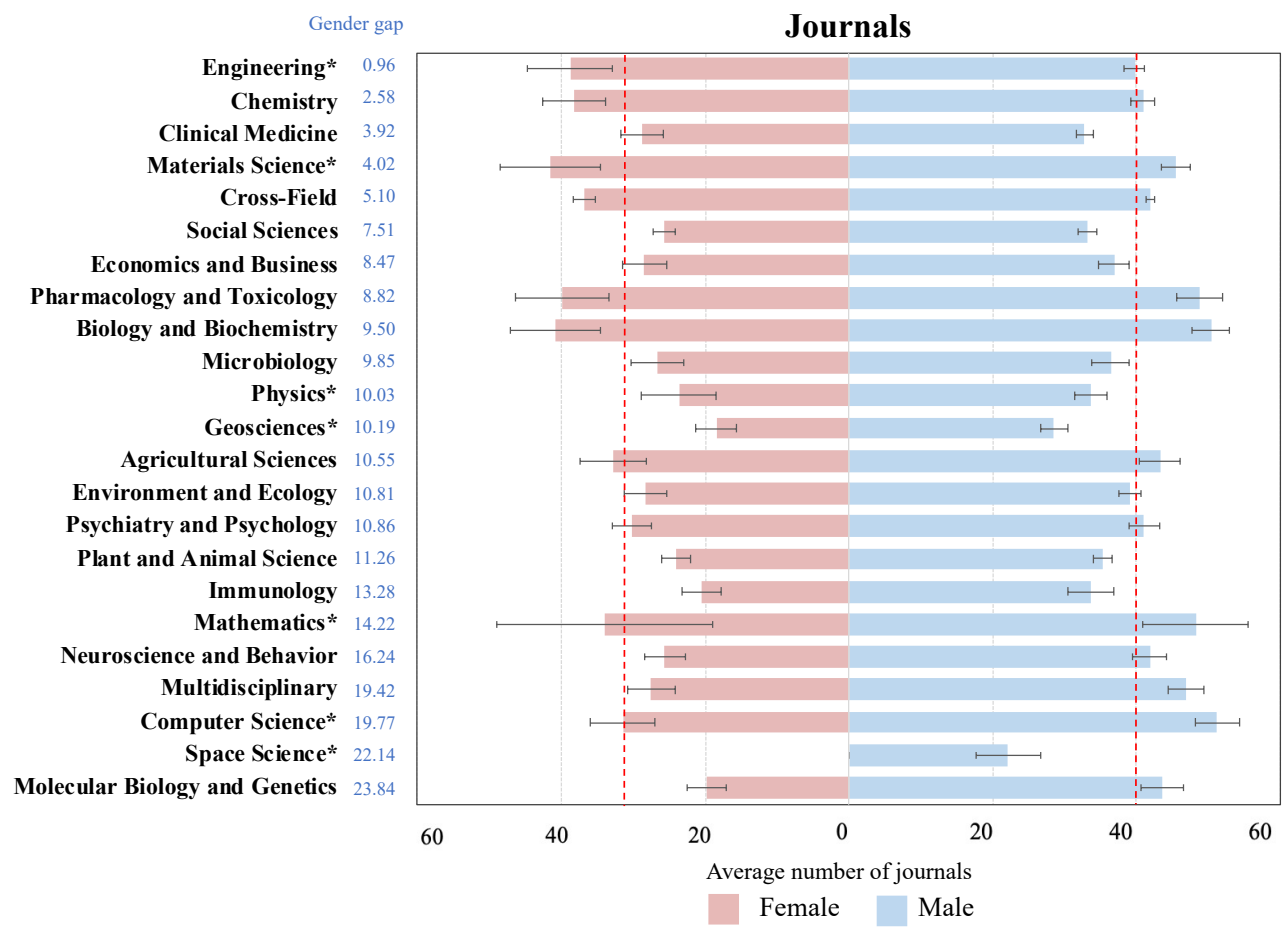

Figure 13. Average number of journals by field of research and gender (\#Journals)

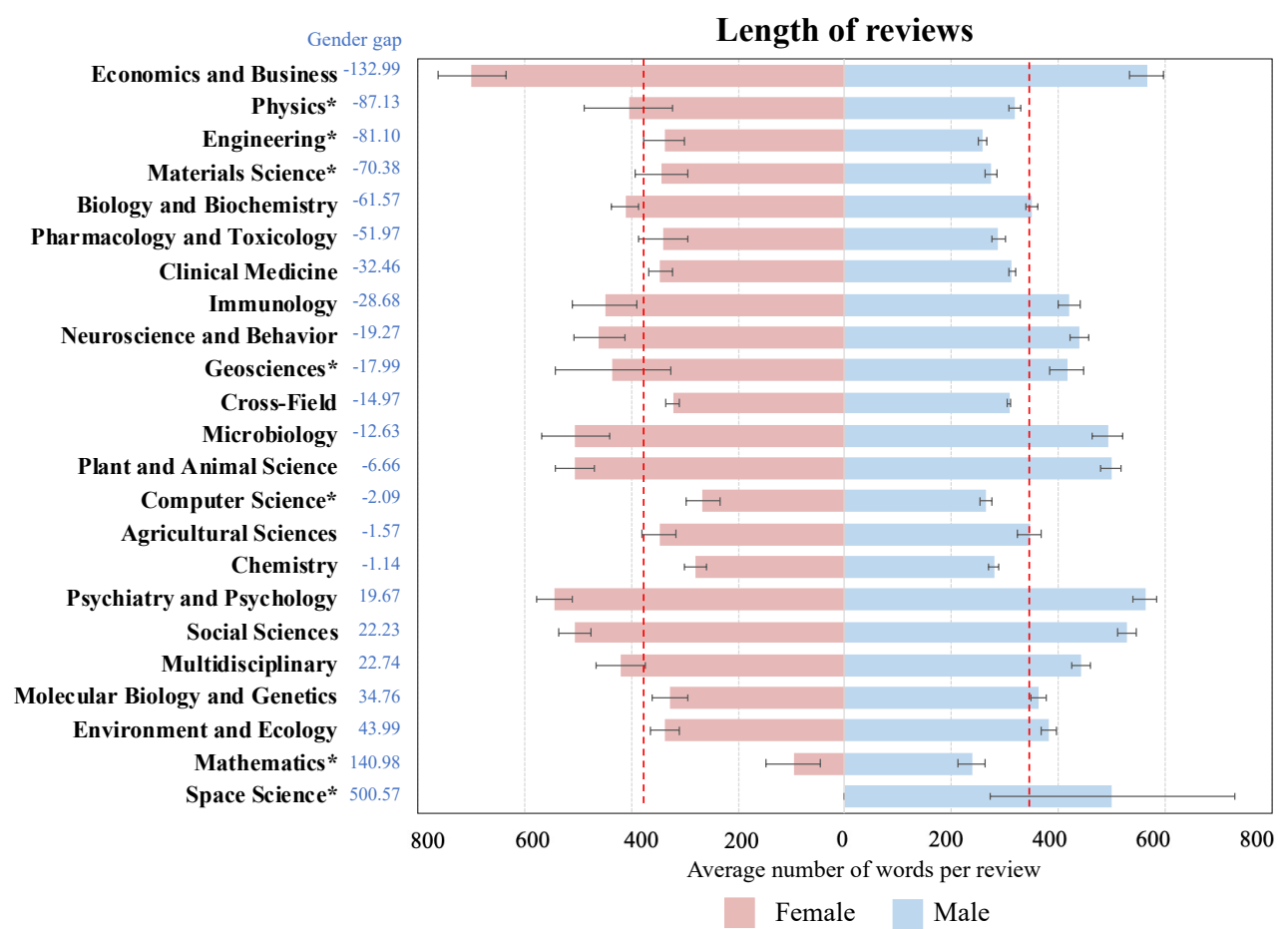

Figure 14. Average length of review by field of research and gender (\#Length)

In terms of research activity (Fig. 15), in most fields, the male reviewers publish more research articles than the female reviewers. The two exceptions are Agricultural Sciences and Geosciences, where women had slightly higher numbers of publications than then men. The 
gender differences in Space Science, Mathematics, and Clinical Medicine are quite clear but less pronounced in Agricultural Sciences, Geosciences and Social Sciences.

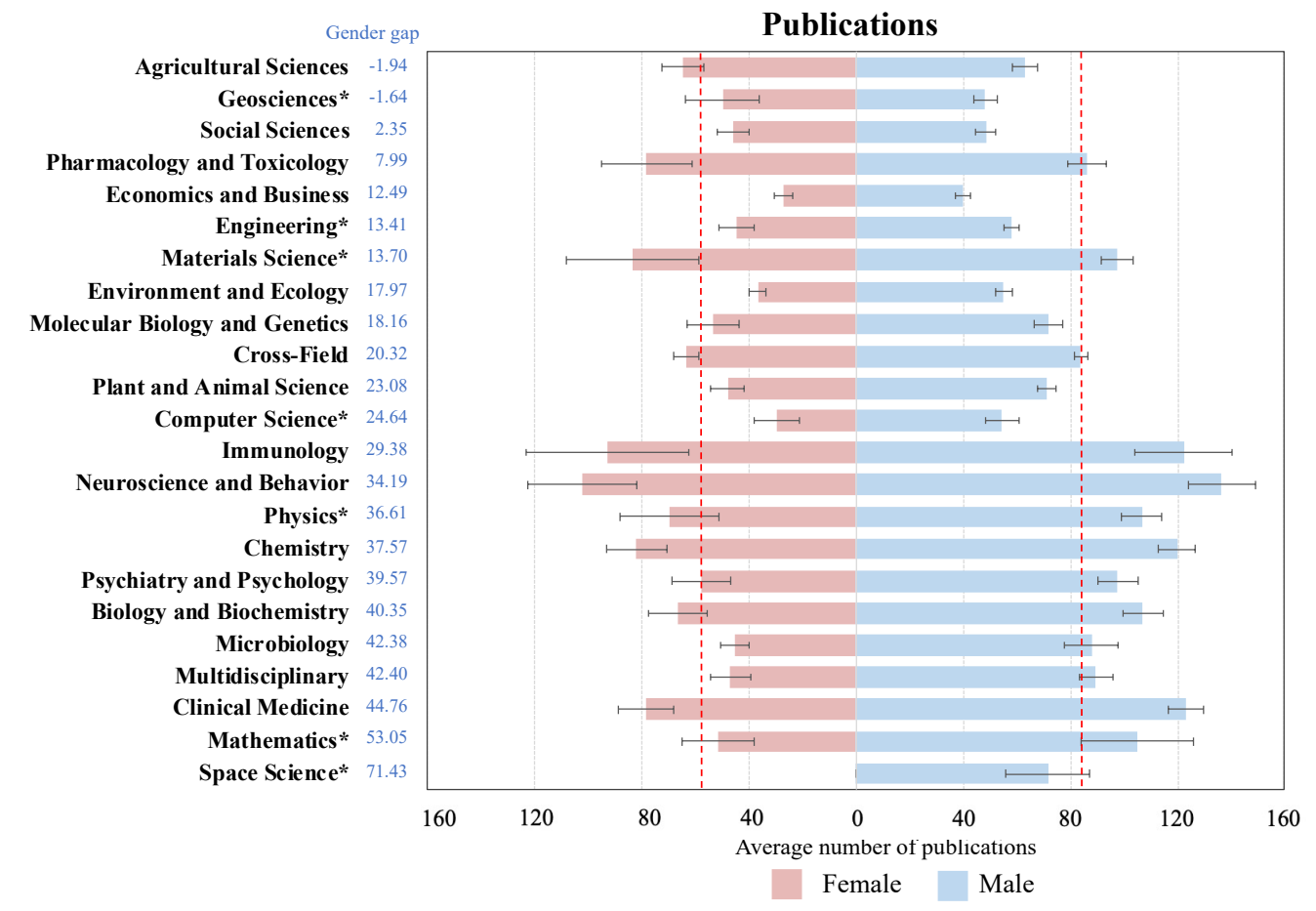

Figure 15. Average number of research publications by field of research and gender (\#Publications)

Consistent with the correlation results at the overall level, there is weak relationship between reviewing and research activity in any research field. (See Table A2 in the Appendix). With coefficients higher than 0.5 between \#Publications and \#Reviews or \#Journals, there two activities seem to be moderate associated in Economics and Business, Molecular Biology and Genetics, Multidisciplinary, Pharmacology and Toxicology, Psychiatry and Psychology. The correlations are stronger internally within reviewing activity alone, where the number of reviews tends to be closely related to the number of journals, especially in Multidisciplinary $(\rho=0.89, p<0.01)$, Molecular Biology and Genetics $(\rho=0.88, p<0.01)$, Pharmacology and Toxicology $(\rho=0.87, \mathrm{p}<0.01)$.

In terms of gender differences, the correlations between reviewing activity and research activity are slightly higher for female reviewers in some research fields (Appendix, Table A3).

\section{Discussion and conclusions}

Our results show that men dominate reviewing roles in all countries and research fields. Moreover, on average, male reviewers produce more reviews, review for more journals, and publish more research articles than their female counterparts. Female reviewers write longer reviews. More specifically, we draw four main conclusions from our analysis: 
First, a regional imbalance of active reviewers is reflected in our results. A large proportion of reviewers work in very high HDI countries. According to previous studies, this phenomenon may be influenced by the reciprocity preference of editors (Fox et al., 2016; Fox \& Paine, 2019; Steinberg et al., 2018). Editors generally favor reviewers from their own geographic region, making peer review geographically biased. Studies also have shown that editors select more reviewers from North America (the United States and Canada) than from any other geographic region (Fox et al., 2016). Female reviewers are underrepresented in all countries, but there are relatively more female reviewers in countries with high HDIs, which perhaps reflects the general gender distribution of researchers. For example, Portugal has the highest proportion of female reviewers, which corresponds to its high ratio of female to male authors compared to 42 other countries around the world (Elsevier, 2020, pp. 12,13). Previous studies have also shown a positive correlation between gender equality and GDP per capita (Jayachandran, 2015). Gender inequality is relatively more prominent in developing countries than in developed countries. Cultural norms, such as patrilocality, may explain the extreme gender gaps in China and some Asian countries (Ebenstein, 2014).

Second, all research fields are dominated by male reviewers. Female reviewers are underrepresented in engineering and the physical sciences, e.g., Mathematics, Geosciences, Materials Sciences, and Computer Science. In health and social sciences, such as Psychiatry and Psychology, Neuroscience and Behavior, Immunology, and Social Sciences, female reviewers are found in relatively higher percentages. Still, the male dominance among reviewers seems to reflect, and perhaps reinforce, female underrepresentation across academia. Females participate in research at varying levels by research field, with relatively higher proportions of females in the biomedical sciences and lower proportions in the physical sciences (Elsevier, 2020, p. 10).

Third, concerning reviewing activity, male reviewers generally have a higher number of reviews and contribute to a higher number of journals as reviewers. This phenomenon is reflected in all research fields in our study. However, in comparison to male reviewers, female reviewers tend to write longer reviews. In 16 of the 23 research fields, female reviewers have a higher number of words per review than males. This may be an indication that female reviewers are more concerned with helping both authors (to advance their work) and editors (in making an informed publishing decision). In research activity, male reviewers publish more research articles than female reviewers, which is seen across almost all research fields. The number of reviews, journals and publications increase with academic experience for both male and female reviewers. However, the average length of a review does not change significantly with increased academic experience. Young reviewers may also provide content-rich reviews. The desire for younger reviewers to seek recognition from influential editors or experts may be one of the reasons for them to bring more enthusiasm on reviewing activity and construct more detailed reviews (Kliewer et al., 2005). 
Fourth, the correlations between reviewing and research activities are weak. neither in general nor within research fields. The few weak associations that we found suggest that reviewing can be understood as a distinct scholarly activity that is different from performing research, which is in line with Ortega's findings (Ortega, 2017).

The results of this study provide a more detailed understanding of the vicious cycle for females in academia. In reviewing activity, there are fewer female reviewers than could be expected from female contributions to research activity in general. Even among these active female reviewers, the academic productivity is lower. One possible reason for this is the potential discrimination of female authors by reviewers/editors in the peer review process, which may affect the outcomes of peer review. As the key components in the scholarly publishing system, both reviewing and research activities reflect the disadvantaged position of females. The interaction between reviewing and research activities may further deepen the vicious circle for females. However, our results also show that reviewing and research activities are not clearly correlated, indicating that reviewers are not necessarily researchers with high academic productivity. This insight can provide us with new ideas for selecting reviewers more consciously to escape the vicious circle for females.

Peer review in scholarly publishing is an important part of the academic ecosystem. Gender inequality in peer review has the potential to affect the overall gender imbalance. The consequences of the vicious cycle for females go beyond females' career advancement. It may also have a negative impact on the quality and outcomes of scientific research. Therefore, it is necessary to turn the vicious circle into the virtuous circle for females. Some efforts to promote gender equality in peer review are already being put into practice. The Lancet and Cell put gender equality high on the agenda (Clark \& Horton, 2019; Narasimhan, 2019). The European Commission, the NIH, and some funding agencies are committed to guaranteeing gender equality in peer review panels (Solans et al., 2020). Increasing gender representation among scientific gatekeepers may improve fairness and equity in peer review results and positively affect the quality and outcomes of scientific research.

This study contains some limitations that need to be addressed. Firstly, as we all know, females are severely underrepresented in academia, which may naturally influence the gender ratio in the group the reviewers. Secondly, nonbinary and transgender reviewers are not contained in our analyses. This does not mean that nonbinary and transgender reviewers are not part of academia. Future research should consider gender diversity more broadly and inclusively. Thirdly, some limitations of using data from Publons in connection with WoS data have been mentioned above. Publons is still a young platform, so its coverage of reviewers may be limited. At the time of data collection, the number of reviewers with a profile on the site appeared to be low in proportion to the number of reviewers. Future research may need to explore some other data sources or platforms related to reviewers, such as F1000 and PubPeer. Further, there are 
still many aspects of gender gaps among reviewers that need to be explored. For instance: How does experience or position affect the reviewing behavior by gender? Does reviewing activity affect career advancement? Is there a better proxy for the quality of a review than its length?

Yet, despite these limitations, there is one important conclusion can clearly be drawn from our results: There is need for concern about gender representation in the quality assurance and gatekeeping functions of scholarly publishing. Such concern should pay attention to all aspects of the reviewing activity. Increasing gender balance among scientific gatekeepers will have implications for scholarly publishing and may improve fairness, equity, and diversity in peer review outcomes and promote scientific progress.

\section{Acknowledgments}

This work was supported by the National Natural Science Foundation of China (Grant Nos. 71974150; 71573085; 72004169), the Major Project of National Social Science Foundation of China (Grant No. 19ZDA349), the National Laboratory Center for Library and Information Science in Wuhan University, and the Research Council of Norway (Grant No. 256223).

\section{References}

Abramo, G., D'Angelo, C., \& Caprasecca, A. (2009). Gender differences in research productivity: A bibliometric analysis of the Italian academic system. Scientometrics, 79(3), 517-539.

Addis, E., \& Villa, P. (2003). The Editorial boards of Italian economics journals: women, gender, and social networking. Feminist Economics, 9(1), 75-91.

Adler, E., Hobbs, A., Dhaliwal, G., \& Babik, J. M. (2020). Gender Differences in Authorship of Clinical Problem-Solving Articles. Journal of Hospital Medicine, 15(8), 475-478.

Amrein, K., Langmann, A., Fahrleitner-Pammer, A., Pieber, T. R., \& Zollner-Schwetz, I. (2011). Women underrepresented on editorial boards of 60 major medical journals. Gender medicine, 8(6), 378-387.

Arruda, D., Bezerra, F., Neris, V., Rocha De Toro, P., \& Wainera, J. (2009). Brazilian computer science research: Gender and regional distributions. Scientometrics, 79(3), 651-665.

Baucom, R. S., Geraldes, A. M., \& Rieseberg, L. H. (2019). Some perspective on Molecular Ecology perspectives: Are women being left out?. Molecular Ecology, 28(10):24512455.

Bendels, M.H., Müller, R., Brueggmann, D., \& Groneberg, D. A. (2018). Gender disparities in high-quality research revealed by Nature Index journals. PloS ONE, 13(1), e 0189136.

Bianchi, F., \& Squazzoni, F. (2015). Is three better than one? simulating the effect of reviewer selection and behavior on the quality and efficiency of peer review. In Proceedings of the 2015 Winter Simulation Conference. (pp.4081-4089).

Black, N., van Rooyen, S., Godlee, F., Smith, R., \& Evans, S. (1998). What makes a good reviewer and a good review for a general medical journal? Jama, 280(3), 231-233.

Borja, Á. (2015). Is there gender bias in the peer-review process in several Elsevier's marine journals? Mar Pollut Bull, 96(1-2), 1-2. 
Bornmann, L., \& Williams, R. (2017). Can the journal impact factor be used as a criterion for the selection of junior researchers? A large-scale empirical study based on ResearcherID data. Journal of Informetrics, 11(3), 788-799.

Bradshaw, C. J., \& Courchamp, F. (2018). Gender bias when assessing recommended ecology articles. Rethinking Ecology, 3, 1-12.

Buckley, H. L., Sciligo, A. R., Adair, K. L., Case, B. S., \& Monks, J. M. (2014). Is there gender bias in reviewer selection and publication success rates for the New Zealand Journal of Ecology? New Zealand Journal of Ecology, 38(2),335-339.

Burke, R. J., \& Mattis, M. C. (2007). Women and minorities in science, technology, engineering, and mathematics: Upping the numbers. Cheltenham, England: Edward Elgar.

Cameron, E. Z., Gray, M. E., \& White, A. M. (2013). Is publication rate an equal opportunity metric? Trends in Ecology \& Evolution, 28(1), 7-8.

Charlin, L., \& Zemel, R. (2013). The Toronto paper matching system: an automated paperreviewer assignment system. In International Conference on MachineLearning (ICML) 2013 Workshop on Peer Reviewing and Publishing Models.

Cho, A.H., Johnson, S.A., Schuman, C.E., Adler, J.M., Gonzalez, O., Graves, S.J., et al. (2014) Women are underrepresented on the editorial boards of journals in environmental biology and natural resource management. PeerJ, 2, e542.

Clark, J., \& Horton, R. (2019). What is The Lancet doing about gender and diversity? The Lancet, 393(10171), 508-510.

Clarivate Analytics. (2018). 2018 global state of peer review. Retrieved from https://doi.org/10.14322/publons.GSPR2018. Accessed 13 March 2020.

Cole, J., \& Zuckerman, H. (1984). The Productivity Puzzle: Persistence and Change in Patterns of Publication Among Men and Women Scientists. In: Steinkamp, MW, Maehr, M. (Eds.): Advances in Motivation and Achievement. Greenwich: JAI Press.

Débarre, F., Rode, N., \& Ugelvig, L. (2018). Gender equity at scientific events. Evolution Letters, 2(3), 148-158.

Demarest, B., Freeman, G., \& Sugimoto, C. R. (2014). The reviewer in the mirror: examining gendered and ethnicized notions of reciprocity in peer review. Scientometrics, 101(1), 717-735.

Doyle, J. M., Quinn, K., Bodenstein, Y. A., Wu, C. O., Danthi, N., \& Lauer, M. S. (2015). Association of percentile ranking with citation impact and productivity in a large cohort of de novo NIMH-funded R01 grants. Molecular psychiatry, 20(9), 1030-1036.

Ebenstein, A. (2014). Patrilocality and missing women. Working Paper, Jerusalem: Hebrew University.

Elsevier (2017). Gender in the global research landscape. Amsterdam, Retrieved from https://www.elsevier.com/research-intelligence/resource-library/ty/gender-in-theglobal-research-landscape. Accessed 13 March 2020.

Elsevier. (2020). The Researcher Journey Through a Gender Lens. Retrieved from: https://www.elsevier.com/research-intelligence/resource-library/gender-report-2020. Accessed 13 March 2020. 
Feramisco, J. D., Leitenberger, J. J., Redfern, S. I., Bian, A., Xie, X.-J., \& Resneck Jr, J. S. (2009). A gender gap in the dermatology literature? Cross-sectional analysis of manuscript authorship trends in dermatology journals during 3 decades. Journal of the American Academy of Dermatology, 60(1), 63-69.

Fox, C. W., Burns, C. S., \& Meyer, J. A. (2016). Editor and reviewer gender influence the peer review process but not peer review outcomes at an ecology journal. Functional Ecology, $30(1), 140-153$.

Fox, C. W., Burns, C. S., Muncy, A. D., \& Meyer, J. A. (2017). Author - suggested reviewers: Gender differences and influences on the peer review process at an ecology journal. Functional Ecology, 31(1), 270-280.

Fox, C. W., Ritchey, J. P., \& Paine, C. T. (2018). Patterns of authorship in ecology and evolution: First, last, and corresponding authorship vary with gender and geography. Ecology and Evolution, 8(23), 11492-11507.

Fox, C. W., \& Paine, C. T. (2019). Gender differences in peer review outcomes and manuscript impact at six journals of ecology and evolution. Ecology and Evolution, 9(6), 35993619.

Fox, C. W., Duffy, M. A., Fairbairn, D. J., \& Meyer, J. A. (2019). Gender diversity of editorial boards and gender differences in the peer review process at six journals of ecology and evolution. Ecology and Evolution, 9(24), 13636-13649.

Ghiasi, G., Larivière, V., \& Sugimoto, C. R. (2015). On the compliance of women engineers with a gendered scientific system. PloS ONE, 10(12), e0145931.

Grod, O. N., Budden, A. E., Tregenza, T., Koricheva, J., Leimu, R., Aarssen, L. W., \& Lortie, C. J. (2008). Systematic variation in reviewer practice according to country and gender in the field of ecology and evolution. PloS ONE, 3(9), e3202.

Helmer, M., Schottdorf, M., Neef, A., \& Battaglia, D. (2017). Gender bias in scholarly peer review. Elife, 6, e21718.

Holman, L., Stuart-Fox, D., \& Hauser, C. E. (2018). The gender gap in science: How long until women are equally represented? PLoS biology, 16(4), e2004956.

Huang, J., Gates, A. J., Sinatra, R., \& Barabási, A.-L. (2020). Historical comparison of gender inequality in scientific careers across countries and disciplines. Proceedings of the national academy of sciences, 117(9), 4609-4616.

Jayachandran, S. (2015). The roots of gender inequality in developing countries. Economics, 7(1), 63-88.

Jubb, M. (2016). Peer review: The current landscape and future trends. Learned Publishing, 29, $13-21$.

Käfer, J., Betancourt, A., Villain, A. S., Fernandez, M., Vignal, C., Marais, G., \& Tenaillon, M. I. (2018). Progress and Prospects in Gender Visibility at SMBE Annual Meetings. Genome biology and evolution, 10(3), 901-908.

Kaltman, J.R., Evans, F.J., Danthi, N.S., Wu, C.O., DiMichele, D.M. \& Lauer, M.S. (2014) Prior publication productivity, grand percentile rank-ing, and topic-normalized citation impact of NHLBI Cardiovascular R01 Grants. Circulation Research, 115, 617-624. 
Karimi, F., Wagner, C., Lemmerich, F., Jadidi, M., \& Strohmaier, M. (2016). Inferring gender from names on the web: A comparative evaluation of gender detection methods. In Proceedings of the 25th International conference companion on World Wide Web (pp. 53-54).

Kliewer, M. A., Freed, K. S., DeLong, D. M., Pickhardt, P. J., \& Provenzale, J. M. (2005). Reviewing the reviewers: comparison of review quality and reviewer characteristics at the American Journal of Roentgenology. American Journal of Roentgenology, 184(6), 1731-1735.

Knobloch-Westerwick, S., Glynn, C. J., \& Huge, M. (2013). The Matilda effect in science communication: an experiment on gender bias in publication quality perceptions and collaboration interest. Science communication, 35(5), 603-625.

Knowles, R., Carroll, J., \& Dredze, M. (2016). Demographer: Extremely simple name demographics. In Proceedings of the Workshop on NLP and Computational Social Science (pp.108-113).

Kovanis, M., Porcher, R., Ravaud, P., \& Trinquart, L. (2016). The global burden of journal peer review in the biomedical literature: Strong imbalance in the collective enterprise. PloS ONE, 11(11), e0166387.

Krawczyk, M., \& Smyk, M. (2016). Author' s gender affects rating of academic articles: Evidence from an incentivized, deception-free laboratory experiment. European Economic Review, 90, 326-335.

Langfeldt, L., Nedeva, M., Sörlin, S., Thomas, D.A. (2020). Co-existing Notions of Research Quality: A Framework to Study Context-specific Understandings of Good Research. Minerva, 58, 115-137.

Larivière, V., Ni, C., Gingras, Y., Cronin, B., \& Sugimoto, C. R. (2013). Bibliometrics: Global gender disparities in science. Nature News, 504(7479), 211-213.

Lerback, J., \& Hanson, B. (2017). Journals invite too few women to referee. Nature News, $541(7638), 455-457$.

Liu, W., \& Ruths, D. (2013). What's in a name? using first names as features for gender inference in twitter. In Analyzing Microtext: 2013 AAAI Spring Symposium.

Liu, X., Suel, T., \& Memon, N. (2014). A robust model for paper reviewer assignment. In Proceedings of the 8th ACM conference on recommender systems (pp.25-32).

Liu, L., Wang, Y., Sinatra, R., Giles, C. L., Song, C., \& Wang, D. (2018). Hot streaks in artistic, cultural, and scientific careers. Nature, 559(7714), 396-399.

Mauleón, E., Hillán, L., Moreno, L., Gómez, I., \& Bordons, M. (2013). Assessing gender balance among journal authors and editorial board members. Scientometrics, 95(1), 87114.

Mendoza-Denton, R., C. Patt, A. Fisher, A. Eppig, I. Young, A. Smith, M. A. Richards. (2017). Differences in STEM doctoral publication by ethnicity, gender and academic field at a large public research university. PLoS ONE. 12(4), e0174296.

Merton, R. K. (1968). The Matthew effect in science: The reward and communication systems of science are considered. Science, 159(3810), 56-63. 
Merton, R. K. (1973). The sociology of science: Theoretical and empirical investigations. Chicago: University of Chicago press.

Mihaljević-Brandt, H., Santamaría, L., \& Tullney, M. (2016). The effect of gender in the publication patterns in mathematics. PloS ONE, 11(10), e0165367.

Milojević, S. (2012). How are academic age, productivity and collaboration related to citing behavior of researchers? PloS ONE, 7(11), e49176.

Morton, M. J., \& Sonnad, S. S. (2007). Women on professional society and journal editorial boards. Journal of the National Medical Association, 99(7), 764-771.

Murray, D., Siler, K., Larivière, V., Chan, W. M., Collings, A. M., Raymond, J., \& Sugimoto, C. R. (2019). Gender and international diversity improves equity in peer review. BioRxiv, 400515.

Narasimhan, S. D. (2019). A commitment to gender diversity in peer review. Cell, 179(1), 1-2.

O'Connor, E. E., Chen, P., Weston, B., Anderson, R., Zeffiro, T., Ahmed, A., \& Zeffiro, T. A. (2018). Gender trends in academic radiology publication in the United States revisited. Academic radiology, 25(8), 1062-1069.

Ortega, J. L. (2017). Are peer-review activities related to reviewer bibliometric performance? A scientometric analysis of Publons. Scientometrics, 112(2), 947-962.

Publons. (2018). Report for Publons State of Peer Review 2018 Survey. Retrieved from https://publons.com/community/gspr\#open-elq-form-slider-DLGSPR. Accessed 13 March 2020.

Reingewertz, Y., \& Lutmar, C. (2018). Academic in-group bias: An empirical examination of the link between author and journal affiliation. Journal of Informetrics, 12(1), 74-86.

Rørstad, K., \& Aksnes, D. W. (2015). Publication rate expressed by age, gender and academic position-A large-scale analysis of Norwegian academic staff. Journal of Informetrics, 9(2), 317-333.

Ross, E. (2017). Gender bias distorts peer review across fields. Nature News. Retrieved from https://doi.org/10.1038/nature.2017.21685. Accessed 13 March 2020.

Santamaría, L., \& Mihaljević, H. (2018). Comparison and benchmark of name-to-gender inference services. PeerJ Computer Science, 4, e156.

Schmaling, K. B., \& Blume, A. W. (2017). Gender differences in providing peer review to two behavioural science journals, 2006-2015. Learned Publishing, 30(3), 221-225.

Shamsi, A. (2020). Gender of Highly Cited Researchers focused on the cross-filed category. Gaceta Sanitaria.

Sivertsen,G.(2018).The Norwegian Model in Norway. Journal of Data and Information Science,3(4) 3-19.

Solans M, Adam P, Vizcaino E, Radó N, Ovseiko P Güell E, et al. (2020). Women's advancement and leadership in the biomedical research centres of Catalonia II: bringing about change. Barcelona: Agència de Qualitat i Avaluació Sanitàries de Catalunya. 
Sotudeh, H., Dehdarirad, T., \& Freer, J. (2018). Gender differences in scientific productivity and visibility in core neurosurgery journals: Citations and social media metrics. Research Evaluation, 27(3), 262-269.

Steinberg, J. J., Skae, C., \& Sampson, B. (2018). Gender gap, disparity, and inequality in peer review. The Lancet, 391(10140), 2602-2603.

Stoet, G., O'Connor, D. B., Conner, M., \& Laws, K. R. (2013). Are women better than men at multi-tasking?. BMC Psychology, 1(1), 1-10.

Thurner, S., \& Hanel, R. (2011). Peer-review in a world with rational scientists: Toward selection of the average. The European Physical Journal B, 84(4), 707-711.

Tite, L., \& Schroter, S. (2007). Why do peer reviewers decline to review? A survey. Journal of Epidemiology \& Community Health, 61(1), 9-12.

United Nations Educational, Scientific and Cultural Organization. (2015). UNESCO science report, towards 2030: executive summary. Retrieved from https://en.unesco.org/unescosciencereport. Accessed 23 March 2021.

United Nations Development Program. (2019). Human Development Report 2019. Retrieved from http://hdr.undp.org/sites/default/files/hdr2019.pdf. Accessed 13 March 2020.

van Arensbergen, P., van der Weijden, I., \& van den Besselaar, P. (2012). Gender differences in scientific productivity, a persisting phenomenon? Scientometrics, 93(3), 857-868.

van Den Besselaar, P., \& Sandström, U. (2016). Gender differences in research performance and its impact on careers: a longitudinal case study. Scientometrics, 106(1), 143-162.

van Den Besselaar, P., \& Sandström, U. (2017). Vicious circles of gender bias, lower positions, and lower performance: Gender differences in scholarly productivity and impact. PloS ONE, 12(8), e0183301.

Walker, K. A. (2020). Females are first authors, sole authors, and reviewers of entomology publications significantly less often than males. Annals of the Entomological Society of America, 113(3), 193-201.

Weisshaar, K. (2017). Publish and perish? An assessment of gender gaps in promotion to tenure in academia. Social Forces, 96(2), 529-560.

West, J. D., Jacquet, J., King, M. M., Correll, S. J., \& Bergstrom, C. T. (2013). The role of gender in scholarly authorship. PloS ONE, 8(7), e66212.

Wickware, P. (1997). Along the leaky pipeline. Nature, 390(6656), 202-203.

Willis, M. (2016). Why do peer reviewers decline to review manuscripts? A study of reviewer invitation responses. Learned Publishing, 29, 5-7.

Wing, D. A., Benner, R. S., Petersen, R., Newcomb, R., \& Scott, J. R. (2010). Differences in editorial board reviewer behavior based on gender. Journal of Women's Health, 19(10), 1919-1923.

World Economic Forum. (2020). The global gender gap report 2020. Retrieved from http://www3.weforum.org/docs/WEF_GGGR_2020.pdf. Accessed 13 March 2020. 
Zeina, M., Balston, A., Banerjee, A., \& Woolf, K. (2020). Gender and ethnic differences in publication of BMJ letters to the editor: an observational study using machine learning. BMJ open, 10(12), e037269.

Zeng, X. H. T., Duch, J., Sales-Pardo, M., Moreira, J. A., Radicchi, F., Ribeiro, H. V., et al. (2016). Differences in collaboration patterns across discipline, career stage, and gender. PLoS biology, 14(11), e1002573. 


\section{Appendix}

Table A1. Percent of women among authors of 15 countries and the EU28 overall in each subject area

\begin{tabular}{c|c|c|c|c|c}
\hline Rank & Subject area & \% of female authors & Rank & Subject area & $\%$ of female authors \\
\hline 1 & Nursing & $63.86 \%$ & 14 & Environmental Science & $35.38 \%$ \\
2 & Psychology & $57.49 \%$ & 15 & Business & $34.12 \%$ \\
3 & Veterinary & $49.64 \%$ & 16 & Chemistry & $32.40 \%$ \\
4 & Immunology and Microbiology & $48.42 \%$ & 17 & Chemical Engineering & $30.57 \%$ \\
5 & Neuroscience & $46.21 \%$ & 18 & Economics & $30.02 \%$ \\
6 & Social Sciences & $45.08 \%$ & 19 & Earth and Planetary Sciences & $26.00 \%$ \\
7 & Medicine & $44.76 \%$ & 20 & Decision Sciences & $24.62 \%$ \\
8 & Pharmacology & $44.74 \%$ & 21 & Materials Science & $21.65 \%$ \\
9 & Health Professions & $44.29 \%$ & 22 & Physics and Astronomy & $18.87 \%$ \\
10 & Arts and Humanities & $43.12 \%$ & 23 & Computer Science & $18.74 \%$ \\
11 & Biochemistry & $42.93 \%$ & 24 & Energy & $18.73 \%$ \\
12 & Agricultural Sciences & $41.99 \%$ & 25 & Engineering & $18.19 \%$ \\
13 & Dentistry & $39.13 \%$ & 26 & Mathematics & $17.97 \%$ \\
\hline
\end{tabular}

Note: The percentage shares are aggregated and calculated on the basis of data provided in Elsevier's gender report (Elsevier, 2020, pp158-159).

Table A2. Spearman's correlation coefficients between reviewing activity and research activity by research field

\begin{tabular}{|c|c|c|c|c|c|c|c|c|c|}
\hline \multicolumn{5}{|c|}{ Agricultural sciences } & \multicolumn{5}{|c|}{ Biology and biochemistry } \\
\hline & Reviews & Journals & Length & Publications & & Reviews & Journals & Length & Publications \\
\hline Reviews & 1 & & & & Reviews & 1 & & & \\
\hline Journals & $0.82 * * *$ & 1 & & & Journals & $0.86^{* * *}$ & 1 & & \\
\hline Length & -0.04 & -0.07 & 1 & & Length & 0.01 & 0 & 1 & \\
\hline Publications & $0.46^{* * *}$ & $0.57^{* * *}$ & 0.04 & 1 & Publications & $0.49 * * *$ & $0.51^{* * *}$ & -0.05 & 1 \\
\hline \multicolumn{5}{|c|}{ Chemistry } & \multicolumn{5}{|c|}{ Clinical medicine } \\
\hline & Reviews & Journals & Length & Publications & & Reviews & Journals & Length & Publications \\
\hline Reviews & 1 & & & & Reviews & 1 & & & \\
\hline Journals & $0.79 * * *$ & 1 & & & Journals & $0.61 * * *$ & 1 & & \\
\hline Length & $0.13 * *$ & $0.20^{* * *}$ & 1 & & Length & -0.05 & $0.11^{* *}$ & 1 & \\
\hline Publications & $0.34 * * *$ & $0.44^{* * *}$ & 0.06 & 1 & Publications & $0.37^{* * *}$ & $0.45^{* * *}$ & $0.09 *$ & 1 \\
\hline \multicolumn{5}{|c|}{ Computer science } & \multicolumn{5}{|c|}{ Cross-field } \\
\hline & Reviews & Journals & Length & Publications & & Reviews & Journals & Length & Publications \\
\hline Reviews & 1 & & & & Reviews & 1 & & & \\
\hline Journals & $0.82^{* * *}$ & 1 & & & Journals & $0.66^{* * *}$ & 1 & & \\
\hline Length & 0 & 0.04 & 1 & & Length & 0.04 & $0.16^{* * *}$ & 1 & \\
\hline Publications & $0.43 * * *$ & $0.61 * * *$ & 0.09 & 1 & Publications & $0.37 * * *$ & $0.46^{* * *}$ & $0.08^{* * *}$ & 1 \\
\hline \multicolumn{5}{|c|}{ Economics and business } & \multicolumn{5}{|c|}{ Engineering } \\
\hline & Reviews & Journals & Length & Publications & & Reviews & Journals & Length & Publications \\
\hline $\begin{array}{l}\text { Reviews } \\
\text { Journals }\end{array}$ & $\begin{array}{c}1 \\
0.71^{* * *}\end{array}$ & 1 & & & $\begin{array}{l}\text { Reviews } \\
\text { Journals }\end{array}$ & $\begin{array}{c}1 \\
0.74^{* * *}\end{array}$ & 1 & & \\
\hline
\end{tabular}




\begin{tabular}{|c|c|c|c|c|c|c|c|c|c|}
\hline Length & -0.15 & $-0.37 * * *$ & 1 & & Length & $0.10 *$ & $0.18 * * *$ & 1 & \\
\hline Publications & $0.52 * * *$ & $0.54 * * *$ & $-0.26^{* * *}$ & 1 & Publications & $0.41 * * *$ & $0.55^{* * *}$ & 0.06 & 1 \\
\hline \multicolumn{5}{|c|}{ Environment and ecology } & \multicolumn{5}{|c|}{ Geosciences } \\
\hline & Reviews & Journals & Length & Publications & & Reviews & Journals & Length & Publications \\
\hline Reviews & 1 & & & & Reviews & 1 & & & \\
\hline Journals & $0.82 * * *$ & 1 & & & Journals & $0.74 * * *$ & 1 & & \\
\hline Length & $0.10^{*}$ & $0.26^{* * *}$ & 1 & & Length & 0.05 & $0.24 * *$ & 1 & \\
\hline Publications & $0.42 * * *$ & $0.55 * * *$ & $0.14 * * *$ & 1 & Publications & $0.36^{* * *}$ & $0.49 * * *$ & $0.28 * * *$ & 1 \\
\hline \multicolumn{5}{|c|}{ Immunology } & \multicolumn{5}{|c|}{ Materials science } \\
\hline & Reviews & Journals & Length & Publications & & Reviews & Journals & Length & Publications \\
\hline Reviews & 1 & & & & Reviews & 1 & & & \\
\hline Journals & $0.86^{* * *}$ & 1 & & & Journals & $0.85^{* * *}$ & 1 & & \\
\hline Length & 0.02 & 0.13 & 1 & & Length & $0.17 * *$ & $0.19 * * *$ & 1 & \\
\hline Publications & $0.37 * * *$ & $0.43 * * *$ & 0.21 & 1 & Publications & $0.41 * * *$ & $0.55^{* * *}$ & -0.02 & 1 \\
\hline \multicolumn{5}{|c|}{ Mathematics } & \multicolumn{5}{|c|}{ Microbiology } \\
\hline & Reviews & Journals & Length & Publications & & Reviews & Journals & Length & Publications \\
\hline Reviews & 1 & & & & Reviews & 1 & & & \\
\hline Journals & $0.78 * * *$ & 1 & & & Journals & $0.82 * * *$ & 1 & & \\
\hline Length & 0.26 & $0.37 * *$ & 1 & & Length & 0.08 & 0.09 & 1 & \\
\hline Publications & 0.29 & 0.33 & -0.04 & 1 & Publications & $0.37 * * *$ & $0.40 * * *$ & 0.15 & 1 \\
\hline \multicolumn{5}{|c|}{ Molecular biology and genetics } & \multicolumn{5}{|c|}{ Multidisciplinary } \\
\hline & Reviews & Journals & Length & Publications & & Reviews & Journals & Length & Publications \\
\hline Reviews & 1 & & & & Reviews & 1 & & & \\
\hline Journals & $0.88^{* * *}$ & 1 & & & Journals & $0.89 * * *$ & 1 & & \\
\hline Length & 0.04 & 0.13 & 1 & & Length & $-0.17 * *$ & -0.08 & 1 & \\
\hline Publications & $0.55^{* * *}$ & $0.54 * * *$ & 0.09 & 1 & Publications & $0.56^{* * *}$ & $0.59 * * *$ & 0.03 & 1 \\
\hline \multicolumn{5}{|c|}{ Neuroscience and behavior } & \multicolumn{5}{|c|}{ Pharmacology and toxicology } \\
\hline & Reviews & Journals & Length & Publications & & Reviews & Journals & Length & Publications \\
\hline Reviews & 1 & & & & Reviews & 1 & & & \\
\hline Journals & $0.72 * * *$ & 1 & & & Journals & $0.87 * * *$ & 1 & & \\
\hline Length & -0.08 & -0.01 & 1 & & Length & -0.07 & -0.04 & 1 & \\
\hline Publications & $0.33 * * *$ & $0.43 * * *$ & -0.15 & 1 & Publications & $0.55^{* * *}$ & $0.60 * * *$ & 0.08 & 1 \\
\hline \multicolumn{5}{|c|}{ Physics } & \multicolumn{5}{|c|}{ Plant and animal science } \\
\hline & Reviews & Journals & Length & Publications & & Reviews & Journals & Length & Publications \\
\hline Reviews & 1 & & & & Reviews & 1 & & & \\
\hline Journals & $0.82 * * *$ & 1 & & & Journals & $0.75^{* * *}$ & 1 & & \\
\hline Length & 0.02 & 0.01 & 1 & & Length & 0.06 & $0.14^{* *}$ & 1 & \\
\hline Publications & $0.38 * * *$ & $0.33 * * *$ & -0.04 & 1 & Publications & $0.46^{* * *}$ & $0.44 * * *$ & -0.02 & 1 \\
\hline \multicolumn{5}{|c|}{ Psychiatry and psychology } & \multicolumn{5}{|c|}{ Social sciences } \\
\hline & Reviews & Journals & Length & Publications & & Reviews & Journals & Length & Publications \\
\hline Reviews & 1 & & & & Reviews & 1 & & & \\
\hline Journals & $0.75 * * *$ & 1 & & & Journals & $0.77 * * *$ & 1 & & \\
\hline Length & -0.02 & $-0.17^{*}$ & 1 & & Length & -0.11 & 0.05 & 1 & \\
\hline Publications & $0.56^{* * *}$ & $0.63 * * *$ & $-0.26 * * *$ & 1 & Publications & $0.52 * * *$ & $0.49 * * *$ & -0.1 & 1 \\
\hline \multicolumn{10}{|c|}{ Space science } \\
\hline & Reviews & Journals & Length & Publications & & & & & \\
\hline Reviews & 1 & & & & & & & & \\
\hline Journals & $0.93 * *$ & 1 & & & & & & & \\
\hline Length & 0.36 & 0.18 & 1 & & & & & & \\
\hline
\end{tabular}


\begin{tabular}{l|l}
\hline Publications & 0.32 \\
\hline
\end{tabular}

0.21

0.46

1

$* * * \mathrm{p}<0.01,{ }^{*} \mathrm{p}<0.05,{ }^{*} \mathrm{p}<0.1$ 
Table A3. Spearman's correlation coefficients between reviewing activity and research activity by research field and gender

\begin{tabular}{|c|c|c|c|c|c|c|c|c|c|}
\hline \multicolumn{5}{|c|}{ Agricultural sciences (Male) } & \multicolumn{5}{|c|}{ Agricultural sciences (Female) } \\
\hline & Reviews & Journals & Length & Publications & & Reviews & Journals & Length & Publications \\
\hline Reviews & 1 & & & & Reviews & 1 & & & \\
\hline Journals & $0.82 * * *$ & 1 & & & Journals & $0.78 * * *$ & 1 & & \\
\hline Length & -0.03 & -0.02 & 1 & & Length & -0.08 & -0.29 & 1 & \\
\hline Publications & $0.48 * * *$ & $0.57 * * *$ & 0.08 & 1 & Publications & $0.46^{* * *}$ & $0.59 * * *$ & -0.12 & 1 \\
\hline \multicolumn{5}{|c|}{ Biology and biochemistry (Male) } & \multicolumn{5}{|c|}{ Biology and biochemistry (Female) } \\
\hline & Reviews & Journals & Length & Publications & & Reviews & Journals & Length & Publications \\
\hline Reviews & 1 & & & & Reviews & 1 & & & \\
\hline Journals & $0.87 * * *$ & 1 & & & Journals & $0.78 * * *$ & 1 & & \\
\hline Length & -0.03 & -0.03 & 1 & & Length & 0.35 & 0.29 & 1 & \\
\hline Publications & $0.52 * * *$ & $0.50 * * *$ & -0.08 & 1 & Publications & 0.32 & $0.62 * * *$ & 0.33 & 1 \\
\hline \multicolumn{5}{|c|}{ Chemistry (Male) } & \multicolumn{5}{|c|}{ Chemistry (Female) } \\
\hline & Reviews & Journals & Length & Publications & & Reviews & Journals & Length & Publications \\
\hline Reviews & 1 & & & & Reviews & 1 & & & \\
\hline Journals & $0.78 * * *$ & 1 & & & Journals & $0.88 * * *$ & 1 & & \\
\hline Length & $0.13 * *$ & $0.20 * * *$ & 1 & & Length & 0.14 & 0.17 & 1 & \\
\hline Publications & $0.32 * * *$ & $0.43 * * *$ & 0.06 & 1 & Publications & $0.45^{* * *}$ & $0.53 * * *$ & 0.09 & 1 \\
\hline \multicolumn{5}{|c|}{ Clinical medicine (Male) } & \multicolumn{5}{|c|}{ Clinical medicine (Female) } \\
\hline & Reviews & Journals & Length & Publications & & Reviews & Journals & Length & Publications \\
\hline Reviews & 1 & & & & Reviews & 1 & & & \\
\hline Journals & $0.60 * * *$ & 1 & & & Journals & $0.74 * * *$ & 1 & & \\
\hline Length & -0.06 & $0.10^{*}$ & 1 & & Length & 0.02 & 0.22 & 1 & \\
\hline Publications & $0.35 * * *$ & $0.44 * * *$ & $0.11 * *$ & 1 & Publications & $0.42 * * *$ & $0.57 * * *$ & 0.07 & 1 \\
\hline \multicolumn{5}{|c|}{ Cross-field (Male) } & \multicolumn{5}{|c|}{ Cross-field (Female) } \\
\hline & Reviews & Journals & Length & Publications & & Reviews & Journals & Length & Publications \\
\hline Reviews & 1 & & & & Reviews & 1 & & & \\
\hline Journals & $0.66^{* * *}$ & 1 & & & Journals & $0.65 * * *$ & 1 & & \\
\hline Length & 0.04 & $0.16^{* * *}$ & 1 & & Length & 0.09 & $0.16^{* *}$ & 1 & \\
\hline Publications & $0.36^{* * *}$ & $0.44 * * *$ & $0.09 * * *$ & 1 & Publications & $0.41 * * *$ & $0.55 * * *$ & 0.07 & 1 \\
\hline \multicolumn{5}{|c|}{ Economics and business (Male) } & \multicolumn{5}{|c|}{ Economics and business (Female) } \\
\hline & Reviews & Journals & Length & Publications & & Reviews & Journals & Length & Publications \\
\hline Reviews & 1 & & & & Reviews & 1 & & & \\
\hline Journals & $0.73 * * *$ & 1 & & & Journals & $0.53 * *$ & 1 & & \\
\hline Length & $-0.20^{*}$ & - & 1 & & Length & 0.23 & -0.21 & 1 & \\
\hline Publications & $0.55 * * *$ & $0.55^{* * *}$ & $-0.21 *$ & 1 & Publications & 0.26 & 0.37 & $-0.45^{*}$ & 1 \\
\hline \multicolumn{5}{|c|}{ Environment and ecology (Male) } & \multicolumn{5}{|c|}{ Environment and ecology (Female) } \\
\hline & Reviews & Journals & Length & Publications & & Reviews & Journals & Length & Publications \\
\hline Reviews & 1 & & & & Reviews & 1 & & & \\
\hline Journals & $0.80 * * *$ & 1 & & & Journals & $0.80 * * *$ & 1 & & \\
\hline Length & 0.03 & $0.20 * * *$ & 1 & & Length & $0.27 * *$ & $0.48^{* * *}$ & 1 & \\
\hline Publications & $0.38 * * *$ & $0.51 * * *$ & 0.1 & 1 & Publications & $0.48 * * *$ & $0.65 * * *$ & $0.28 * *$ & 1 \\
\hline \multicolumn{5}{|c|}{ Immunology (Male) } & \multicolumn{5}{|c|}{ Immunology (Female) } \\
\hline & Reviews & Journals & Length & Publications & & Reviews & Journals & Length & Publications \\
\hline Reviews & 1 & & & & Reviews & 1 & & & \\
\hline Journals & $0.86^{* * *}$ & 1 & & & Journals & $0.71 * * *$ & 1 & & \\
\hline
\end{tabular}




\begin{tabular}{|c|c|c|c|c|c|c|c|c|c|}
\hline Length & 0.01 & 0.06 & 1 & & Length & -0.01 & 0.34 & 1 & \\
\hline Publications & 0.29 & $0.36 * *$ & 0.17 & 1 & Publications & 0.38 & $0.62 * *$ & 0.17 & 1 \\
\hline \multicolumn{5}{|c|}{ Microbiology (Male) } & \multicolumn{5}{|c|}{ Microbiology (Female) } \\
\hline & Reviews & Journals & Length & Publications & & Reviews & Journals & Length & Publications \\
\hline Reviews & 1 & & & & Reviews & 1 & & & \\
\hline Journals & $0.83 * * *$ & 1 & & & Journals & 0.56 & 1 & & \\
\hline Length & 0.06 & 0.06 & 1 & & Length & 0.03 & 0.28 & 1 & \\
\hline Publications & $0.37 * * *$ & $0.40 * * *$ & 0.16 & 1 & Publications & -0.14 & 0.16 & -0.04 & 1 \\
\hline \multicolumn{5}{|c|}{ Molecular biology and genetics (Male) } & \multicolumn{5}{|c|}{ Molecular biology and genetics (Female) } \\
\hline & Reviews & Journals & Length & Publications & & Reviews & Journals & Length & Publications \\
\hline Reviews & 1 & & & & Reviews & 1 & & & \\
\hline Journals & $0.89 * * *$ & 1 & & & Journals & $0.77 * * *$ & 1 & & \\
\hline Length & -0.04 & 0.03 & 1 & & Length & $0.43 *$ & $0.67 * * *$ & 1 & \\
\hline Publications & $0.52 * * *$ & $0.54 * * *$ & 0 & 1 & Publications & $0.53 * * *$ & $0.54 * * *$ & $0.50 * *$ & 1 \\
\hline \multicolumn{5}{|c|}{ Multidisciplinary (Male) } & \multicolumn{5}{|c|}{ Multidisciplinary (Female) } \\
\hline & Reviews & Journals & Length & Publications & & Reviews & Journals & Length & Publications \\
\hline Reviews & 1 & & & & Reviews & 1 & & & \\
\hline Journals & $0.89 * * *$ & 1 & & & Journals & $0.88 * * *$ & 1 & & \\
\hline Length & $-0.16^{* *}$ & -0.07 & 1 & & Length & -0.29 & -0.17 & 1 & \\
\hline Publications & $0.54 * * *$ & $0.59 * * *$ & 0.06 & 1 & Publications & $0.58 * * *$ & $0.48 * *$ & -0.3 & 1 \\
\hline \multicolumn{5}{|c|}{ Neuroscience and behavior (Male) } & \multicolumn{5}{|c|}{ Neuroscience and behavior (Female) } \\
\hline & Reviews & Journals & Length & Publications & & Reviews & Journals & Length & Publications \\
\hline Reviews & 1 & & & & Reviews & 1 & & & \\
\hline Journals & $0.70 * * *$ & 1 & & & Journals & $0.83^{* * *}$ & 1 & & \\
\hline Length & -0.03 & 0.04 & 1 & & Length & -0.3 & -0.12 & 1 & \\
\hline Publications & $0.25^{* *}$ & $0.39 * * *$ & -0.15 & 1 & Publications & $0.63 * * *$ & $0.56^{* * *}$ & -0.1 & 1 \\
\hline \multicolumn{5}{|c|}{ Pharmacology and toxicology (Male) } & \multicolumn{5}{|c|}{ Pharmacology and toxicology (Female) } \\
\hline & Reviews & Journals & Length & Publications & & Reviews & Journals & Length & Publications \\
\hline Reviews & 1 & & & & Reviews & 1 & & & \\
\hline Journals & $0.87 * * *$ & 1 & & & Journals & $0.87 * * *$ & 1 & & \\
\hline Length & -0.04 & -0.01 & 1 & & Length & -0.16 & -0.14 & 1 & \\
\hline Publications & $0.55^{* * *}$ & $0.59 * * *$ & 0.06 & 1 & Publications & $0.52 * *$ & $0.59 * * *$ & 0.12 & 1 \\
\hline \multicolumn{5}{|c|}{ Plant and animal science (Male) } & \multicolumn{5}{|c|}{ Plant and animal science (Female) } \\
\hline & Reviews & Journals & Length & Publications & & Reviews & Journals & Length & Publications \\
\hline Reviews & 1 & & & & Reviews & 1 & & & \\
\hline Journals & $0.75^{* * *}$ & 1 & & & Journals & $0.68 * * *$ & 1 & & \\
\hline Length & 0.09 & $0.16^{* *}$ & 1 & & Length & -0.09 & 0.07 & 1 & \\
\hline Publications & $0.43 * * *$ & $0.43^{* * *}$ & -0.02 & 1 & Publications & $0.52 * * *$ & $0.43 * *$ & 0.13 & 1 \\
\hline \multicolumn{5}{|c|}{$\begin{array}{c}\text { Psychiatry and psychology (Male) } \\
\end{array}$} & \multicolumn{5}{|c|}{ Psychiatry and psychology (Female) } \\
\hline & Reviews & Journals & Length & Publications & & Reviews & Journals & Length & Publications \\
\hline Reviews & 1 & & & & Reviews & 1 & & & \\
\hline Journals & $0.72 * * *$ & 1 & & & Journals & $0.79 * * *$ & 1 & & \\
\hline Length & 0.02 & -0.15 & 1 & & Length & -0.1 & -0.18 & 1 & \\
\hline Publications & $0.46^{* * *}$ & $0.58 * * *$ & $-0.26 * * *$ & 1 & Publications & $0.58 * * *$ & $0.59^{* * *}$ & -0.26 & 1 \\
\hline \multicolumn{5}{|c|}{ Social sciences (Male) } & \multicolumn{5}{|c|}{ Social sciences (Female) } \\
\hline & Reviews & Journals & Length & Publications & & Reviews & Journals & Length & Publications \\
\hline Reviews & 1 & & & & Reviews & 1 & & & \\
\hline Journals & $0.75^{* * *}$ & 1 & & & Journals & $0.80 * * *$ & 1 & & \\
\hline Length & $-0.17 * *$ & 0.03 & 1 & & Length & 0.06 & 0.16 & 1 & \\
\hline
\end{tabular}




\begin{tabular}{l|llll|l|llll} 
Publications & $0.48 * * *$ & $0.48 * * *$ & -0.1 & 1 & Publications & $0.62 * * *$ & $0.50 * * *$ & -0.1 & 1 \\
\hline
\end{tabular}
$* * * \mathrm{p}<0.01, * * \mathrm{p}<0.05, * \mathrm{p}<0.1$

Note: Seven of the 23 research fields had fewer than 10\% female reviewers - Computer Science, Engineering, Geosciences, Materials Science, Mathematics, Physics and Space Science. No further analysis of these fields was conducted because, with so few numbers, the results would not be conclusive. 